\title{
Estimation of renewable energy and built environment-related variables using neural networks - a review
}

\author{
Eugénio Rodrigues ${ }^{\mathrm{a}, *}$, Álvaro Gomes ${ }^{\mathrm{b}}$, Adélio Rodrigues Gaspar ${ }^{\mathrm{a}}$, Carlos Henggeler Antunes ${ }^{\mathrm{b}}$ \\ ${ }^{a}$ ADAI, LAETA, Department of Mechanical Engineering, University of Coimbra \\ Rua Luís Reis Santos, Pólo II, 3030-788 Coimbra, Portugal \\ ${ }^{b}$ INESC Coimbra. Department of Electrical and Computer Engineering, University of Coimbra \\ Rua Sílvio Lima, Pólo II, 3030-290 Coimbra, Portugal
}

\begin{abstract}
This paper presents a review on the application of neural networks for the estimation, forecasting, monitoring, and classification of exogenous environmental variables that affect the performance, salubrity, and security of cities, buildings, and infrastructures. The forecast of these variables allows to explore renewable energy and water resources, to prevent potentially hazardous construction locations, and to find the healthiest places, thus promoting a more sustainable future. Five research themes are covered-solar, atmospheric, hydrologic, geologic, and climate change. The solar section comprises solar radiation, direct and diffuse radiation, infrared and ultraviolet radiation, clearness index, and sky luminance and luminous efficacy. The atmospheric section reviews wind, temperature, humidity, cloud classification, and storm prediction. The hydrologic section focuses on precipitation, rainfall-runoff, hail, snow, drought, flood, tides, water levels, and other variables. The geologic section covers works on landslides, earthquakes, liquefaction, erosion, soil classification, soil mechanics, and other properties. Finally, climate change forecasting and downscaling of climate models are reviewed. This work demonstrates the wide range of applications of these methods in different research fields. Some research gaps and interdisciplinary research opportunities are identified for future development of comprehensive forecast and evaluation approaches regarding the estimation of renewable energy and built environment-related variables.

Keywords: neural network, solar variables, hydrologic variables, atmospheric variables, geologic variables, climate change
\end{abstract}

\footnotetext{
${ }^{*}$ Corresponding author.

Email address: erodrigues@uc.pt (Eugénio Rodrigues)
} 


\section{Contents}

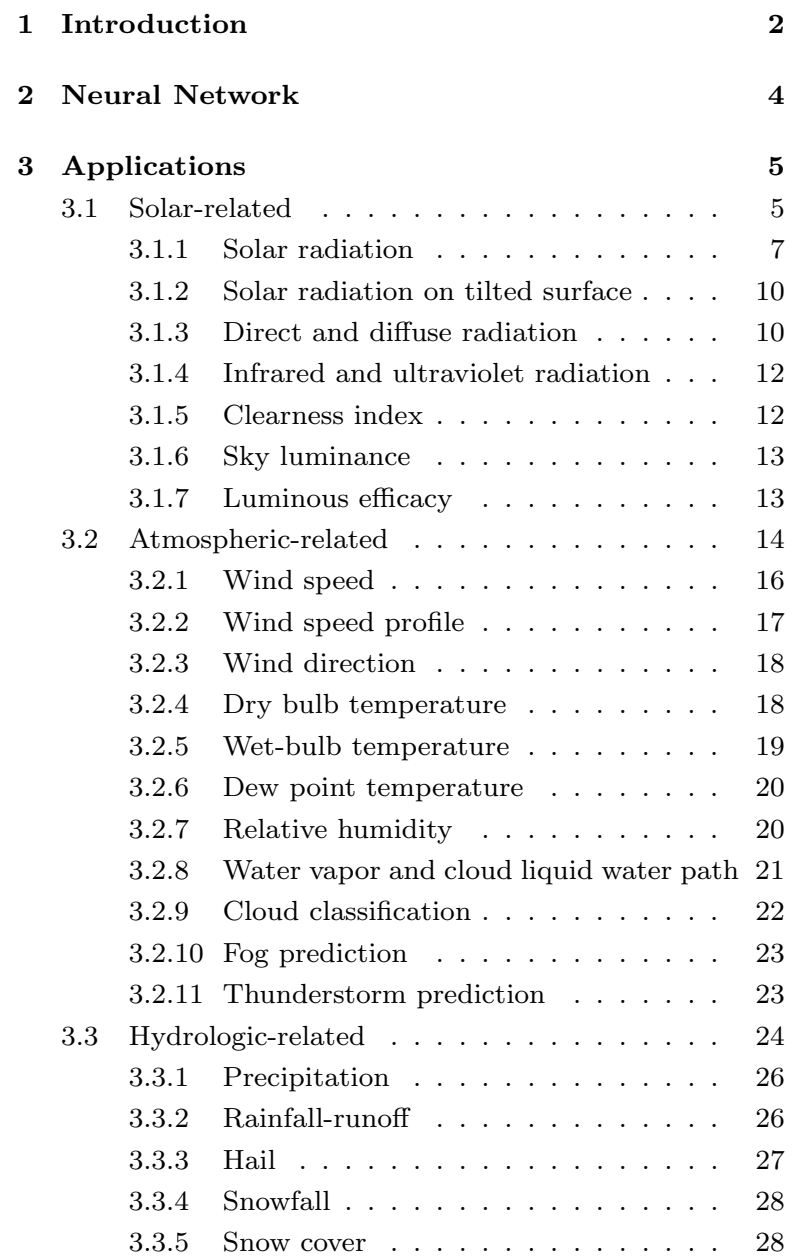

\begin{tabular}{lll}
\hline 3.3 .6 & Snow depth and snow water equivalent 29
\end{tabular}

3.3 .7 Evapotranspiration . . . . . . . . . . . 29

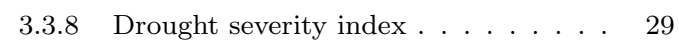

3.3 .9 River flow . . . . . . . . . . . . 30

3.3 .10 Flood . . . . . . . . . . . . . 30

3.3 .11 Wave height . . . . . . . . . . . . 30

3.3 .12 Tide level . . . . . . . . . . . . . . . . . 31

3.3 .13 Groundwater level . . . . . . . . . . . 31

3.3 .14 Lake level . . . . . . . . . . . . . . . 32

3.3 .15 Reservoir inflow. . . . . . . . . . . . . 32

3.3 .16 Sediments concentration . . . . . . . . . . 32

3.3 .17 Salinity . . . . . . . . . . . . 33

3.3 .18 Water temperature . . . . . . . . . . 33

3.4 Geologic-related. . . . . . . . . . . . . . . . 33

$3.4 .1 \quad$ Landslide susceptibility . . . . . . . . 34

$\begin{array}{lll}3.4 .2 & \text { Earthquake classification. . . . . . . . . } 35 & 35\end{array}$

3.4 .3 Liquefaction prediction . . . . . . . . 36

$3.4 .4 \quad$ Erosion estimation . . . . . . . . . . . 37

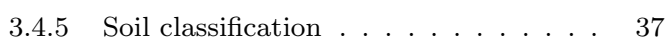

3.4 .6 Subsurface cavities . . . . . . . . . . . 38

3.4 .7 Soil mechanics . . . . . . . . . . . 38

$3.4 .8 \quad$ Soil organic matter. . . . . . . . . . 39

3.4 .9 Soil organic carbon. . . . . . . . . . . . . 40

3.4 .10 Ground temperature . . . . . . . . . . . . 40

3.4.11 Thermal resistivity . . . . . . . . . . . 40

3.4 .12 Thermal conductivity . . . . . . . . 41

3.4 .13 Electric resistivity . . . . . . . . . . . 41

3.4 .14 Hydraulic properties . . . . . . . . . . 41

3.5 Climate change . . . . . . . . . . 42

\begin{tabular}{|ll|}
\hline 4 & Discussion \\
\hline
\end{tabular}

5 Conclusion 44

\section{Introduction}

This paper presents a review on the application of neural networks for the estimation, forecasting, monitoring, and classification of renewable energy and other environment-related variables that affect the built environment. Contrarily to other reviews on these methods, the purpose of this work was not to complete an in-depth literature review of a particular application topic (e.g. HVAC systems, building energy consumption, or solar radiation) but rather to carry out a transversal review on their application in different fields that are relevant to a sustainable built environment. The main purpose of this approach is to interrelate topics that are naturally connected, such as solar and atmospheric, or hydrologic and geologic, but that are typically addressed in literature as isolated subjects.

Besides the estimation of energy-related variables allowing to plan and explore renewable energy resources - i.e., by predicting the solar potential of a region, prevailing winds and speed, stream flows, reservoir levels, tide levels, biomass distribution on land, and geothermal potential — and the forecast of water-related variables that allow to manage the water resources - i.e., by estimating fu- 
ture precipitation, reservoir levels, groundwater levels, snow depth and land cover, and droughts-, a sustainable built environment is dependent, among other factors, on guaranteeing the safety and quality of the natural resources and land use. Therefore, other environment-related variables were also covered, such as the occurrence of storms and their severity, flash floods, seashore water levels, water quality (sediments concentration and salinity levels), stability of soils (landslide susceptibility, liquefaction of soils, subsurface cavities, soil mechanics), soil erosion process estimation, soil classification, and determination of organic matter.

Some variables have an impact on the sustainability of the built environment and should not be analyzed autonomously. For instance, estimating the solar radiation on buildings surfaces and simultaneously predicting cloud cover and classification allows an accurate dimensioning of renewable solar devices (i.e., photovoltaics and thermal collectors) and the development of smart energy management systems. Whenever wind speed and direction profiles are added to the estimation process, hybrid systems can be considered as well. The accurate prediction of sky clearness and luminance allows the satisfaction of indoor visual comfort in buildings, thus reducing the consumption of electric energy by artificial lighting. Other atmospheric variables, such as ambient temperature and relative humidity, have impact on the thermal comfort in buildings, thus their accurate forecast may help in designing more energy efficient buildings and managing renewable energy according to the occurrence of heat waves or other extreme weather events. Additionally, the prediction of future climate change scenarios allows the design of more robust buildings and cities. Therefore, the objectives of this study were: to analyze and review the most important works that cover a wide range of environment-related variables that are exogenous to the builtenvironment but affect the performance, safety, and salubrity of cities, buildings, energy systems and infrastructures; to identify future opportunities and gaps for interdisciplinary research for the development of comprehensive forecast and evaluation approaches that take into account the various interrelated elements of the environment.

As expected, the number of articles published is vast. For this reason, a document selection methodology was used. The first step entailed the exhaustive collection of papers published in international journals and/or conference proceedings. From these, a total of 1658 documents (including review papers) were selected and classified into distinct groups according to the learning algorithm output variables. For each document, the number of citations was determined and in each group the documents were ranked by citations. The articles with the highest number of citations published after 1999 were selected.

After this introductory section, the Neural Network section provides the reader with the basic information on the modeling, terminology, and estimation accuracy indicators of the models. In the Applications section, five main themes are analyzed. The first four themes are related to 
solar (covers $14 \%$ of total documents), atmospheric (14\%), hydrologic (53\%), and geologic (17\%) problems. The fifth is related to the forecast of climate changes $(2 \%)$. Each theme is divided into groups according to the estimated variables. The number of documents and percentage per group are listed in Table 1. Evidently, some groups emerge as the main research topic within each theme, such as solar radiation, wind speed, precipitation and runoff, and soil mechanics for solar, atmospheric, hydrologic, and geologic-related themes, respectively. Even though the topic division may seem clearly delineated, assigning some of the groups within each theme was not as easy, as their boundaries are not clearly defined (e.g. should precipitation prediction be included in the hydrologic or the atmospheric subsection?). Ultimately, the documents were assigned according to the estimated phenomena. Lastly, a discussion on the articles analyzed is presented, followed by the conclusions.

\section{Neural Network}

Since the 1950s, when Turing [1] idealized that machines could learn, learning algorithms have been developed and applied in several problems. One of those is the artificial neural network, which consists of interconnected units called neurons, nodes, or perceptrons [2]. The perceptrons were formulated by Rosenblatt [3] as being capable of containing information in the connections and, therefore, possess the capability to memorize and recognize patterns. In a network, the neuron has as input the output values of the preceding neurons. The incoming weighted values are summed and an activation function is applied to the total-logistic sigmoid, hyperbolic tangent, tan-sigmoid, wavelet, Gaussian, softmax, threshold, and identity functions, just to mention a few - to limit the amplitude of the neuron output.

There are several types of neural networks [4. For instance, the simplest one is the linear network (LN), which comprises just two layers for input and output variables, or more complex and popular multi-layer perceptron network (MLP), which may have one or more hidden layers with different number of neurons. The selection of the activation function depends on the kind of modeling data and scale of values.

However, for the neural network to work properly, the network weights must be optimized. This process is called calibration or training. Two of the most common training algorithms are the standard back-propagation [5] and the Levenberg-Marquardt [6], which change the network weights in the direction of minimizing the differences between the model's predicted values and the aimed values. Recently, population-based evolutionary algorithms have also been used, such as genetic algorithms (GA), differential evolution, and particle swarm optimization (PSO) techniques. After the training phase, the models must be validated and tested against unseen data-usually a part of the original dataset. To assess their accuracy, statistical performance indicators are used. However, 
different analysis is required depending on the type of model, whether it is a regression-it fits a set of estimated values with observed ones - or if it is a classification problem-identifying the class the input fits into. For regression problems, the indicators are usually the correlation coefficient, coefficient of determination, residual sum of squares, mean square error, root mean square error, coefficient of variation, mean bias error, mean percent error, mean absolute error, and mean absolute percentage error. If time series are estimated, the indicator may be the autocorrelation coefficient. When dealing with classification problems, the common performance indicators are the probability of detection, probability of false detection, false alarm rate, Kuipers skill score, and Odds ratio. For further details on statistical performance indicators, please see Haykin [4] and Wilks [7].

Other neural network types are the radial basis function network (RBF) [8], general regression neural network (GRNN) 9], recurrent neural networks (RNN), adaptive neuro-fuzzy inference system (ANFIS) [10, support vector machine (SVM) [11, probabilistic neural network (PNN) [12], self-organizing feature maps (SOFM) [13], neural network ensembles [14, and extreme learning machines (ELM) [15. Neural networks acronyms and abbreviations are presented in Table 2 .

\section{Applications}

\subsection{Solar-related}

Solar-related estimations allow engineers, architects, urban planners, and other decision makers to plan, design, and create systems to explore and manage renewable resources, design more energy efficient buildings, and to build cities with better environmental quality. Global solar radiation estimation, as also its direct and diffuse components, allows to determine the solar energy potential of a specific region and to predict the upcoming solar energy production variation. This is also important to determine the solar availability in buildings and how the energy consumption for heating and cooling will vary in the near future. When estimated over tilted surfaces, renewable energy systems can be accurately dimensioned to match the energy demand. Lastly, sky clearness, sky luminance and luminous efficacy forecasts contribute to design passive measures in buildings to prevent the unnecessary use of artificial light or prevent indoor visual discomfort, thus promoting energy efficiency in buildings.

The accurate prediction of solar radiation for a specific location is dependent on several factors, such as the sky conditions and time of the day. As locally measured data is not always available, forecasting and estimation models are the most cost-effective solutions. These can be empirical models, statistical methods, satellite-based methods, and artificial intelligence models.

The Ångström approach, and its variations, is the most used empirical model and correlates the global radiation to the clear-sky radiation, or to the extraterrestrial radiation on the horizontal 
surface, and the sunshine duration fraction. However, these models are dependent on location, thus limiting their applicability in other regions [16]. When the sunshine duration is not available, the models can use the ambient temperature and the relative humidity instead, which is especially useful in humid and coastal regions. The statistical methods use past local information to predict the future solar radiation. Despite being easy to model and presenting good short-term accuracy, the statistical methods fail as the prediction period increases. The satellite-based methods use regression equations to correlate information, such as the cloud cover, obtained from the satellite imagery with the clear sky index. The benefit of satellite-based approaches is that they cover large areas at different wavelengths and provide more accurate information than interpolation techniques [17].

Artificial intelligence models are particularly suitable for local scale and short-term predictions due to their nonlinear mapping capability between input and output variables. However, for these models to work properly, and in order to be applicable in practice, the model type and structure, as well as the type of input variables, have to be correctly determined. For instance, Yadav et al. [18] studied the selection of the most relevant meteorological and geographical parameters to be used as input variables by testing three neural networks. The work focused on 26 Indian locations with different climatic conditions and the most relevant input variables were altitude above mean sea level, temperature, maximum and minimum temperature, and sunshine hours. Latitude and longitude had minimum influence on solar radiation prediction. Amrouche and Le Pivert [19] developed a neural network approach to forecast the global horizontal irradiance for locations with no available measured data on records. This type of approach was developed taking into consideration the applicability of the method; thus the input variables, which were tested at the same time, were the global horizontal radiations and forecasted ambient temperatures. The authors tested several model structure topologies, with the same computation burden in training, and concluded that ambient temperatures, contrarily to what was previously assumed, do not bring much more additional information. According to the authors, the uniqueness of the approach is the ability to continuously learn and acquire knowledge from the measurements of neighboring locations, despite the weak initial training.

As the topology of the models affect the accuracy performance, several authors are currently studying new approaches, for example by hybridizing SVM with a radial basis function [20, a firefly algorithm [21, or a wavelet transform algorithm [22]. Mohammadi et al. 22] combined a wavelet transform algorithm to decompose time series into different components thus enhancing the capacity of the model to capture the information at different levels. Despite the importance of the topology, the authors refer that the right choice of input variables was important, thus they selected relative sunshine duration, difference between air temperatures, relative humidity, average 
temperature, and extraterrestrial solar radiation. For the long-term forecast in a particular day of the year, Mohammadi et al. 23] implemented an ANFIS approach that had a single input variable and a single output variable (the day's horizontal global solar radiation). The advantage of this approach was that no meteorological data or pre-calculation analysis was required. Lately, ELM have been used to predict horizontal global solar radiation [24], as these require lesser time to train and have shown to have better accuracy prediction than SVM and Artificial Neural Networks $(\mathrm{ANN})$.

Neural networks have been used since the 1990s to estimate solar-related variables [25]27], and the growing interest has led several researchers to review past contributions 28 38].

In this first subsection, forecasting/estimation of global solar radiation, solar radiation on tilted surface, diffuse and direct radiation, infrared and ultraviolet radiation, clearness index, and sky luminance and luminous efficacy are addressed in detail. Tables 3 and 4 summarize the papers analyzed in this subsection by listing the authors, model type, input variables, output variables, location, and statistical accuracy of the models.

\subsubsection{Solar radiation}

Mellit and Pavan [39] modeled an MLP to forecast next day 24-hour solar irradiance in Trieste, Italy. The input variables were the day of the year, mean air temperature, and mean solar irradiance of that day. The MLP had two hidden layers with 11 and 17 neurons. The output variables were 24, each corresponding to one hour of the next day. The model was trained using the LevenbergMarquardt algorithm with $K$-fold cross-validation $(K=10)$. The training dataset consisted of the hourly data from July 1st 2008 to May 23rd 2009 and from November 23rd 2009 to January 24th 2010. The authors concluded that the model predicts well for short-term sunny days but only presents acceptable results for cloudy ones.

Sfetsos and Coonick [40] modeled and compared different neural networks and traditional linear methods for a single step ahead forecasting of hourly solar radiation for the island of Corsica, France. The neural networks were the LN, two MLP networks trained with different algorithms, the RBF network, Elman RNN, and an ANFIS. The training data consisted of $984 \mathrm{~h}$ and the testing data of $312 \mathrm{~h}$ of measured meteorological information. The learning algorithm with the best performance was the MLP trained by the Levenberg-Marquardt algorithm. The activation function was a logistic function. The MLP consisted of 5 input variables - time, wind direction, and the values $t-1, t-2$, and $t-24$. A single hidden layer was used with 4 neurons. As the prediction included night time, thus incorporating non-continuity in the data, the authors concluded that MLP dealt better with these problems. They also stated that the MLP and ANFIS forecasting methods benefit from having the wind direction in the input variables. 
Tymvios et al. [41] compared the capability of seven MLPs and three Ångström regressions in estimating the global solar radiation in Cyprus. The MLP models differed in the number of hidden layers (one or two) and in the number and type of variables in the input layer. The MLP with the best result had three input variables - theoretical daily sunshine duration, measured daily sunshine duration, and daily maximum temperature - and consisted of two hidden layers with 46 and 23 neurons. The neurons were activated with the hyperbolic tangent function. The training data consisted of 1858 days of a total of 2090 days of measured solar radiation and the training algorithm was the back-propagation. Cross-validation was used to determine the model convergence with 232 days of the remaining data. The authors then concluded that the MLP performance was comparable to the best Ångström models, thus could easily substitute the latter ones, which were more demanding of input data and difficult to use by non-experts.

Reddy and Ranjan [42] built an MLP for estimation of monthly mean daily and hourly values of solar global radiation in New Delhi and Mangalore, India. The model structure had 9 input variables - latitude, longitude, altitude, month, hour, air temperature, relative humidity, wind speed, and rainfall. Two hidden layers were used with 8 and 7 neurons, while the output variable was the hourly global radiation. The training algorithm was the back-propagation with the weight of the neurons optimized using the generalized delta rule. The activation function was the sigmoid function. The data consisted of the measured meteorological information of 11 locations, from which two locations were used for testing the model. The authors compared this with other regression models, such as the Ångström, Hargreeves, and Supit models, and the MLP outperformed all. The authors then concluded that the neural network was more suitable for solar radiation prediction.

Mellit et al. 43] modeled a wavelet-network (WN) with an impulse infinite-response filter to predict the daily total solar-radiation from time series data in Algeria. Several model structures were tested and compared. The structure that presented the best performance had an input layer with 5 variables, one hidden layer with 10 neurons, and a single output variable. The five input variables were the 5 preceding values of total solar radiation of the one being estimated, which makes it suitable for short-term prediction. The Morlet's function was used as the activation function. The steepest descent algorithm was used in the training process. The training data was 19 years of measured data, extending from 1981 to 2000, gathered from a meteorological station in Algeria. Measured data from 2001 was used to test the performance of the model. The structure found in second place consisted of 25 input variables, one hidden layer with 10 neurons, and 5 output variables in the output layer. The input variables were the first 25 total daily radiation values and the output variables were the following 5 values. The authors concluded that the model was suitable to fill missing data and the main advantage in comparison to other neural networks 
was the speed of convergence of the technique.

Paoli et al. 44 developed an MLP network to predict time-series of daily solar radiation for Ajaccio in the Corsica Island, France. The authors pre-processed the meteorological data before using it to model the neural network. According to the authors, this strategy helps to improve the accuracy of the model. The ad hoc time series pre-processing had 3 steps. In the first step, the dataset had removed the measuring errors (substituted by the hourly average of the 19 years for the given day), and in steps two and three the clear sky was corrected and the extraterrestrial values were normalized, respectively. The training dataset was measured from the year 1971 to 1987 . The testing data were collected between 1988 and 1989. The structure of the MLP was 8 input variables - the 8 previous values of solar radiation $(t-1, \cdots, t-8)$-and one hidden layer with 2 neurons. The activation function for the hidden layers was the Gaussian function. When compared with other methods, such as Naive predictor, the Markov Chain, Bayes, and other autoregressive methods, the model outperformed them all. The authors concluded that pre-processing of the data improved the neural network accuracy by reducing the error margin by $5 \%$ to $6 \%$.

Rehman and Mohandes [45] modeled three MLPs with different input variables for the estimation of global solar radiation. The comparison of the three models showed that the best one had three input variables - time, day of the year, daily mean air temperature, and relative humidity. A single hidden layer was used with 24 neurons. A single output variable was used for the estimation of global solar radiation, and the activation function was the sigmoid function. The training algorithm was the back-propagation algorithm. The training dataset was 1462 days (from year 1998 to 2001) and testing dataset was 240 days (2002) of measured information from the Abha city in Saudi Arabia. The authors stated that the model could be used in locations where only temperature and humidity were available.

Sözen et al. [46] developed nine feedforward neural networks (FNN) with biases trained by different algorithms to generate monthly solar maps of Turkey. To achieve this, the authors used the same 6 input variables-latitude, longitude, altitude, month, mean sunshine duration, and mean temperature - and a single output variable corresponding to the estimated solar radiation. However, the number of hidden layers and neurons in each layer varied. The activation function was a sigmoid function. The training algorithms used were Scale Conjugate Gradient, LevenbergMarquardt, and Pola-Ribiere Conjugate Gradient. The training and testing datasets consisted of meteorological data measured between the years 2000 and 2002 obtained from 17 stations (11 stations for training and 6 for testing). The authors concluded that the models had enough accuracy for scientists to locate and design solar energy systems in Turkey. 


\subsubsection{Solar radiation on tilted surface}

Mehleri et al. [47] built an RBF model for the prediction of the mean solar irradiance on inclined surfaces in Athens, Greece. Meteorological information from a weather station for the full year of 2004 was used as a dataset. The input variables were the tilt angle and orientation. The model was trained using a fuzzy-means algorithm (10 fuzzy sets showed the best results) to minimize the deviation between the measured and predicted values by automatically optimizing the number of neurons in the hidden layer, their center, and output weights. The meteorological data was divided into $75 \%$ for training and $25 \%$ for testing. The authors observed that the RBF showed better accuracy than the linear model that was also tested.

\subsubsection{Direct and diffuse radiation}

Marquez and Coimbra [48] developed four FNNs to estimate the direct solar irradiance in California's Central Valley, USA. Eleven input variables were employed-maximum temperature, temperature, minimum temperature, dew point temperature, relative humidity, sky cover, wind speed, wind direction, probability of precipitation, cosine of the solar zenith angle, and the normalized hour angle. A GA was used to select which variables to use in each FNN model. The first model $\left(\mathrm{FNN}_{3}\right)$ consisted of three input variables - sky cover, minimum temperature, and normalized hour angle. The second model $\left(\mathrm{FNN}_{6}\right)$ had three additional input variables-maximum temperature, dew point temperature, and probability of precipitation. The third model $\left(\mathrm{FNN}_{8}\right)$ had two more - temperature and wind speed. The last model $\left(\mathrm{FNN}_{11}\right)$ had all variables. The output variables were the direct normal irradiance for the same-day, 1, 3, and 5-days ahead. The training algorithm was the Levenberg-Marquardt algorithm. The modeling dataset consisted of collected data between November 1, 2008, and November 30, 2009, from the National Digital Forecast Database and measured data from the solar observatory of the University of California Merced. The training dataset consisted of $80 \%$ randomly selected points and the remaining ones were used for testing. The authors concluded that the prediction of direct solar irradiance was more difficult to obtain than global solar radiance and that the models' accuracy decreased with the increase of the forecasting horizon. However, the accuracy in summer months did not decrease so sharply. The inclusion of normalized hour angles improved the models' accuracy.

Soares et al. [49] modeled and compared three MLP networks to predict hourly diffuse solar radiation in São Paulo city, Brazil. The model was trained and tested using meteorological dataglobal solar radiation, diffuse solar radiation, long-wave atmospheric emission, air temperature, relative humidity, and atmospheric pressure - measured between 1998 and 2002. The difference between the models consisted in having the long-wave atmospheric emission as input variable and a pattern selection mechanism to pre-process the data. Every hourly interval vector of input 
variables was a pattern. The sigmoid function was used as the activation function. The MLP was trained by the back-propagation algorithm, and the testing phase used data from the year 2002 . The best model had the long-wave atmospheric emission in the input variables - the remaining inputs were the theoretical solar radiation at the atmosphere top, global solar radiation, relative humidity, partial pressure of the water vapor, theoretical solar azimuth angle, and theoretical zenith angle. According to the authors, the fact that this model incorporated the long-wave radiation improved its accuracy and may be used as surrogate for the cloud cover variable.

López et al. [50] developed an MLP, with a Bayesian framework of automatic relevance determination, to predict the direct solar radiation at Desert Rock, USA, between 1998 and 1999 . The Bayesian approach allows determining the relevance of every input variable and controls the weights connecting each input variable to the hidden layer. Thus, this approach can turn off variables that are not relevant for the estimation. The input layer had 9 variables to be studied - cosine of solar zenith angle, relative optical air mass, clearness index, air temperature, dew point temperature, relative humidity, precipitable water, wind speed, and pressure. A single hidden layer was used and two models were built, one with two neurons and the other with ten. The neurons in the hidden layer were activated by the hyperbolic tangent function and the output layer by the identity function. The authors observed that from all input variables, the clearness index was the most relevant one, followed by the relative optical air mass. Relative humidity showed to be a minor input variable. Wind speed, pressure, precipitable water, and dew point temperature were irrelevant when compared to the clearness index. The authors concluded that the model with less hidden neurons was more suitable to identify the relevant variables.

Elminir et al. [51] developed two MLP networks for the prediction of the hourly diffuse radiationfor Aswan, South-Valley, and Cairo in Egypt — and the daily diffuse radiation - for Aswan only. The hourly prediction model was trained with measured data from between 1999 and 2002 and evaluated with data from 2003. The daily prediction model was trained with data from the years 1999 to 2001 and tested with data from 2002. The data was preprocessed to remove inconsistent measurements or unverified pyrometer data. The hourly MLP had 5 input variables - normalized values of month of the year, day of the month, hour of the day, hourly value of global radiation, and hourly value of the extraterrestrial irradiation. The structure of the second model, the daily MLP model, only had 3 input variables - daily global radiation, daily extraterrestrial irradiation, and sunshine fraction. Both models had a single hidden layer with 40 neurons that were activated by a logistic sigmoid function. The models were trained using back-propagation algorithm. The authors compared these results with others obtained from regression models for diffuse solar radiation and concluded these were more accurate and faster in the prediction.

Mellit et al. [52] developed and compared an FNN and an adaptive model for predicting global, 
direct, and diffuse hourly solar irradiance in Jeddah, Saudi Arabia. The neural network had four input variables - air temperature, sunshine duration, relative humidity, and the previously estimated output variable - single output value. Three versions were created; each version estimated a different variable - the global irradiance, direct irradiance, or diffuse irradiance - and had a different number of hidden neurons-17, 12, and 15 neurons in a single layer, respectively. The neurons were activated by the sigmoid function. The FNN was trained by the Levenberg-Marquardt algorithm using 8000 points of measured data and tested using 765 points for each parameter obtained between 1998 and 2002 (sunshine duration was synthesized by the authors). The adaptive model $(\alpha$-model $)$ was based on techniques used in finance and stock exchange applications. The authors concluded that despite obtaining better results from the FNN models, the $\alpha$-model was easier and more flexible if there was a need to add or remove parameters.

\subsubsection{Infrared and ultraviolet radiation}

Elminir et al. [53] built an ANN for the prediction of the solar radiation components - infrared radiation, ultraviolet radiation, and global insolation - for the region of Helwan and Aswan, Egypt. The six variables in the input layer were the wind speed, wind direction, ambient air temperature, relative humidity, cloud cover, and water vapor. The activation function in the single hidden layer with 10 hidden neurons was a logistic sigmoid function. The output layer had 3 variables. The ANN was trained using the back-propagation algorithm. The training set was recorded at the Helwan site during 2001 (full year) and 2002. The evaluation of the performance was carried out for the measured data for Aswan from January to November 2002. The authors concluded that the model had high accuracy in unseen data; however, they recognized the necessity to extend the model to other regions.

Jacovides et al. [54] developed and compared several FNN models to estimate the spectral global ultraviolet, global photosynthetic photon flux density, and broadband global radiant flux. The input variables resulted from the combination of several parameters - sunshine fraction, air temperature, predictable water, extraterrestrial radiation, relative humidity, air mass, and ozone amount. All models had only one hidden layer. The training and testing data were collected for the semi-urban Athalassa site, Cyprus, between 2004 and 2006. Two-year data were used for training and one-year data for testing. The training algorithm was the Levenberg-Marquardt algorithm. The authors concluded that sunshine duration played an important role in the models' accuracy and some other parameters were able to negatively influence the performance of the model.

\subsubsection{Clearness index}

Dorvlo et al. [55] modeled and compared an MLP and an RBF network to predict the clearness index in Oman. Both models had the same input variables - month of the year, latitude, longitude, 
altitude, and sunshine ratio. The number of hidden layers in the MLP models varied between 1 and 3. The single output variable was the clearness index, which is the ratio between the total solar radiation on the surface and the extraterrestrial solar radiation. The training and testing of the models were carried out with average data from eight stations collected in ten years (1986-1998). Data from two of those stations were used in testing. The MLP used the logistic sigmoid function as the activation function while the RBF used the Gaussian function. The MLP was trained using the Bayesian regulation back-propagation algorithm. The RBF was trained by optimizing the Gaussian function nodes center, width, and weight. These were initially calculated and computed using multiple linear regression techniques. Despite not having significant differences between the two models, the authors recommend the RBF as it requires less computation power.

Mellit et al. [56] developed an ANFIS for the estimation of sequences of mean monthly clearness index data in Algeria. The input variables were the geographical coordinates of the site - altitude, longitude, and latitude. The output variables were the 12 -month values of clearness index. The database used in the ANFIS system consisted of 12 sets of monthly solar radiation collected in 60 sites. The training method was a combination of back-propagation, gradient-descent, and a leastsquares algorithm in a two-pass process over a number of epochs. The ANFIS had better accuracy than prediction maps from B-spline function. The authors concluded that the main advantages of this model were the capability to predict the clearness index just from geographical parameters, while requiring a lower computation time in the training process.

\subsubsection{Sky luminance}

Janjai and Plaon [57] developed an MLP model to predict the sky luminance in the tropical climate of Thailand. The input variables were solar zenith angle, zenith angle of the sky element, and angular distance between the sky element and the sun. The output variable was the relative sky luminance. The training and testing of the model were carried out using scanned sky data from Nakhon Pathom and Songkhla solar stations, Thailand. The training set corresponded to two years of measurements (2007 to 2008) at Nakhon Pathom. The model was tested to predict one year of measurements (2009) at Nakhon Pathom and at Songkhla. The training was carried out using the back-propagation algorithm. Three sky types were tested for the two locations - clear sky, partly cloudy, and overcast. When comparing the results with the ones from the Centre International d'Eclairage model, the authors concluded that the MLP outperformed in all cases except in the partly cloudy sky type.

\subsubsection{Luminous efficacy}

López and Gueymard [58] developed several MLP models for the estimation of luminous efficacy of direct, diffused, and global solar radiation under cloudless conditions. The input layer included a 
combination of several parameters - diffuse fraction, direct transmittance, precipitable water, and solar zenith angle. The number of neurons in the hidden layer varied between 3 and 22 . The output layer had 3 variables for the corresponding luminous efficacy components. The activation function for the hidden layer was the hyperbolic tangent transform while for the output layer it was the identity function. A synthetic dataset was used to train and test the model using a spectral radiative transfer model for cloudless atmospheres. The training algorithm was a Gauss-Newton based Levenberg-Marquartd algorithm. From all the modeled neural networks, the one with the best performance had 22 hidden neurons; however, the authors preferred the model with 10 hidden neurons to reduce model complexity without significant loss of accuracy. The authors observed that relative errors were larger than $5 \%$ when solar elevation, irradiance, and illuminance were very low.

\subsection{Atmospheric-related}

The prediction of atmospheric-related phenomena is important not only to plan and design renewable energy systems but also to predict outdoor environment conditions that affect the buildings performance, thus allowing to design passive and active mechanisms to control indoor environment. The wind variables - speed and direction - and the temperature/humidity-related variables - dry bulb temperature, wet-bulb temperature, and relative humidity - indicate some of the outside conditions that affect the buildings performance and, consequently, influence the occupants' behavior. Knowing how these factors will vary in the near future helps to predict the increase in the energy demand. However, this information can also be used to predict the amount of renewable energy that can be produced from wind energy, which is relevant in the context of integrated management of energy resources in the realm of smart grids, namely to deal with the intermittency of this energy source. The cloud cover classification, fog and storm prediction allow to determine the impact on the solar availability in buildings, thus anticipating the increase of energy consumption. However, weather exhibits strong variations and fluctuations that make forecasting very difficult and uncertain with large deviations from the real values.

In addition to artificial intelligence models, there are other prediction models, such as the persistence method, physical methods, statistical methods, and spatial correlation models [59 62 . In the persistence method, the future wind speed is assumed to remain the same, thus being simple and prone to error approach, as time span increases. Usually, this method only works for ultra-short-term forecasts (from minutes to 1-hour ahead). The physical methods were developed for large scale weather prediction areas, which use ambient temperature, air pressure, surface roughness and landscape obstacles information to have a detailed description of the atmosphere phenomena. Statistical methods use the historical data of a site to perform short-term predictions. 
Some common techniques are the autoregressive (AR), autoregressive moving average (ARMA), and Bayesian approaches. The spatial correlation models predict a variable behavior at a specific site from the measurements on the surrounding locations.

However, to overcome the difficulties in dealing with non-linearity and complexity of atmospheric prediction, researchers studied the use of artificial intelligence models, such as neural networks, as surrogate methods to traditional methods. Early studies applied these soft techniques to cloud classification [63 66], wind speed forecast [67-69], and storm prediction [70, 71].

Researchers are now focusing their work on hybridizing the prediction models [72 77, which may combine one or several methods at different stages of the forecast process to select the best input variables, to filter or to identify data with the right information, and to optimize the parameters of the model.

As in all kinds of prediction problems, the model type, topology, and input variables contribute significantly to the accuracy of the model. For instance, recently, Ren et al. [78 developed an approach to find the optimal input parameters in back-propagation neural network model optimized by a particle swarm optimization technique. The input variables were selected using the lateral data selection method and the longitudinal data selection. By selecting the appropriate input parameters, the proposed approach clearly outperformed common back-propagation neural networks. Instead of decomposing the data, Azad et al. 79 incorporated a pattern recognition mechanism into a hybrid ensemble of ANNs and statistical models to predict a year ahead over the identified patterns of the previous years. Another approach is to prepare data using an image recognition algorithm. Liu et al. [80] applied an adaptive boosting algorithm before the forecast was carried out with an ensemble of MLPs.

The use of optimization techniques to enhance the forecast performance of the neural networks were tested by Liu et al. [81, who used a GA to improve an SVM to ensure the generalization capabilities of the model. The authors also used selection methods for the input data by using deep quantitative analysis and wavelet transformation to decompose the input data signal into the required components. Instead of GA, Meng et al. 82 used a crisscross optimization algorithm to improve ANN capabilities. Liu et al. 83 applied a secondary decomposition algorithm to the original wind data before using an Elman RNN model that already used a wavelet packet and a fast ensemble empirical mode decomposition. Chen and Yu [84 combined an SVM and an unscented Kalman filter to predict short-term capabilities. The SVM was used to formulate a nonlinear statespace model before the Kalman filter was used to perform dynamic state estimation. According to the authors, the proposed method has much better performance than other tested approaches.

Past reviews on atmospheric forecast models using artificial intelligence can be found in refs. [35, 36, $59,62,85,89]$. 
In this second subsection, the review on the atmospheric-related variables is divided into wind speed, wind direction, dry bulb temperature, wet-bulb temperature, dew point temperature, relative humidity, water vapor, cloud classification, fog prediction, and the forecasting of thunderstorms. Tables 5, 6, and 7 summarize the analyzed works.

\subsubsection{Wind speed}

Mohandes et al. [90] modeled one SVM and one MLP to predict the wind speed in Medina city, Saudi Arabia. The input variables were a set of values of wind speed from previous days. The values tested varied between 1 and 11. For the MLP model, the number of hidden neurons ranged between 2 and 100 and neurons were activated by the tan-sigmoid function. The training and testing data of wind speed measurements covers a period of 12 years between 1970 and 1982 . Two thousand days were used for training, 1500 days for cross-validation, and 728 days for testing. The MLP was trained using the Levenberg-Marquardt algorithm. For both models, the number of input variables was the same, corresponding to the 11 previous days of wind speed. The authors concluded that SVM outperforms MLP in all cases.

Sfetsos 91] built and compared the performance of eight neural networks - LN, two MLPs trained by different algorithms, RBF, Elman RNN, ANFIS, and two neural logic networks (NLN) with and without logic rules - for the prediction of time-series of mean hourly wind speed in Odigitria, Greece. The models used the measured data from March 1996 (a total of $744 \mathrm{~h}$ ). The LN was trained using Widrow-Hoff rule. The MLP models were trained by the back-propagation (MLPBP) or by the Levenberg-Marquardt algorithm (MLP-LM). The MLP-BP had 6 hidden neurons and the MLP-LM had 4. The RBF used the Gaussian density function to activate the 35 hidden neurons. The ANFIS had five layers and nine rules. The NLN had no hidden neurons, and the RNN had three hidden neurons as well as the remaining NLN with logic rules (NLN-LR). Despite the MLP-LM and NLN-LR having similar accuracy, the MLP-LM only required $5 \mathrm{~s}$ of computation time, as opposed to the $141 \mathrm{~s}$ verified for the NLN-LR model.

Barbounis et al. 92 developed three neural networks, with internal feedback paths, to produce four nodes - North (N), East (E), South (S), and West (W) - for online 72-hours ahead time-series of wind forecast in Crete, Greece. The first model was an infinite impulse response MLP (IIRMLP), the second a local activation feedback multi-layer network (LAF-MLN), and the final one was a diagonal RNN. The seven input variables were wind speed and direction, for the N, E, and $\mathrm{W}$ nodes, and an input index. The IIR-MLP and LAF-MLN models had two hidden layers with 7 and 8 neurons, respectively. The diagonal RNN had only one hidden layer with 32 self-recurrent neurons. The activation function was the hyperbolic tangent. The neural networks were trained by a proposed algorithm called global recursive prediction error. The training and testing data were 
arranged in batches of 72-hour node predictions for wind speed measurements composed of 3264 patterns and 960 patterns, respectively. When compared to other models, such as the static MLP and finite impulse neural network, the authors concluded that the three models outperformed the static ones and had a good forecast capability.

More and Deo 93 built two neural network types to forecast time-series of wind speed in the Colaba coastal region, Mumbai, India. The first type was an FNN trained by two methods - the back-propagation (FNN-BP) and cascade correlation algorithms (FNN-CC). The second type was a Jordan RNN. Each network type was modeled three times, each per time period-monthly (FNN$\mathrm{BP}_{m}, \mathrm{FNN}_{-} \mathrm{CC}_{m}$, and $\left.\mathrm{RNN}_{m}\right)$, weekly $\left(\mathrm{FNN}^{-\mathrm{BP}_{w}}, \mathrm{FNN}-\mathrm{CC}_{w}\right.$, and $\left.\mathrm{RNN}_{w}\right)$, and daily $\left(\mathrm{FNN}-\mathrm{BP}{ }_{d}\right.$, FNN-CC ${ }_{d}$, and $\left.\mathrm{RNN}_{d}\right)$. The models had past wind speed values as input variables $(t-1, \cdots, t-n)$ and for the output variable the wind speed at time $t$. A dataset for training and testing of daily average values of wind speeds measured over 12 years between 1989 and 2000 was used. The first 10 years served to train the models and the last 2 years to test. The best model for monthly prediction was the $\mathrm{RNN}_{m}$ with a structure of 4 input variables, three hidden layers with 6 , 7 , and 6 neurons. The authors concluded that the proposed models were able to capture the rising and falling trends of the observed wind speed time-series.

Li and Shi 94 modeled and compared the performance of three neural networks for time-series forecast of wind speed in Hannaford and Kulm, North Dakota, USA. The first model was an MLP, the second one was an RBF, and the last one was an adaptive linear element (ADALINE) neural networks. A different number of input variables and training rates were tested to determine the best models. The output of all the models was the next hourly average wind speed. The training and testing data was measured with some anemometers at fixed positions having different heights. One-year (2002) of data was collected and the hourly values were averaged. The authors concluded that determining the best-performance model was difficult, as the structure and learning rates produced differences in accuracy. Therefore, they recommend the development of a more robust method of combining forecasts from different ANN models.

\subsubsection{Wind speed profile}

Mohandes et al. 95] developed an ANFIS model to estimate the wind speed profile up to $100 \mathrm{~m}$, based on 10, 20, 30, and 40 m, in Juaymah city, Saudi Arabia. The model had lower altitude wind speed values as inputs, 10 Gaussian membership functions, 5 fuzzy rules, and a single output variable - wind speed. The training and testing dataset was comprised of measurements taken at 10,20,30, and $40 \mathrm{~m}$ above ground level for a period of 17 months between July 1, 2006 and November 30, 2007. The model was trained using wind speed values at three heights and asked to estimate the following height. For example, the model used 10, 20, and $30 \mathrm{~m}$ wind speed values to 
predict the wind speed at $40 \mathrm{~m}$. Three scenarios were built; for each, a $10 \mathrm{~min}$ wind speed average value, a 10 min average over 1 month, and daily average values over the entire data collection were used. The authors concluded that the model was capable of estimating wind speeds at higher altitudes using values from the lower ones.

\subsubsection{Wind direction}

Potter and Negnevitsky [96] implemented an ANFIS for the forecast of 2.5 min ahead time-series of wind vectors in Tasmania, Australia. The membership function was the Gaussian function. The learning algorithms were the least-squares estimator and the gradient descent method. The training and testing used data from a 21-month time series in steps of 2.5 min. When compared with a persistence model, which was used by the wind power generation industry for short-term prediction, the ANFIS obtained a much better result.

Tagliaferri et al. 97] developed an SVM and an MLP model for the prediction of wind direction for very short-time periods. Both models had a wind direction vector (in degrees) of past data as input variables. As output variables, the models used a vector of wind directions averaged over $1 \mathrm{~min}$ ahead and averaged between $1 \mathrm{~min}$ and $2 \mathrm{~min}$ ahead. The input vector length, number of hidden layers, and number of hidden neurons were optimized to find the best structure. The MLP was activated by the hyperbolic tangent function. The dataset used to train and test the models were registered during the 34th America's Cup in 2013, San Francisco, for 34 days. Wind speed and direction were measured from moving and fixed positions at a frequency of $5 \mathrm{~Hz}$. The models were tested using the last 100 min of recorded data. The authors concluded that the SVM allowed for a better accuracy in forecast and computation time. However, if more computation power was available, the MLP model could have obtained better results.

\subsubsection{Dry bulb temperature}

Tasadduq and Rehman 98 developed an MLP model to predict the hourly ambient temperature of the next day at a determined time for the coastal region of Jeddah, Saudi Arabia. The input variable was a single ambient temperature value at a specific time. The output variable was the ambient temperature in the following day at the same time. A single hidden layer with four neurons was used. The back-propagation algorithm trained the model with one year of hourly temperature values. The testing dataset corresponded to three years of measured data different from the one used in training. The authors concluded that the model was a valuable tool for hourly temperature prediction.

Hayati and Mohebi [99] built an MLP model to forecast short-term dry temperature for Kermanshah city, Iran. The input variables were wet bulb temperature, dry bulb temperature, wind speed, relative humidity, pressure, sunshine, and solar radiation. The output was the next day dry 
bulb temperature. A single hidden layer was used with 6 neurons. The tan-sigmoid transfer function was used for the hidden neurons and the linear function for the output variables. The training method was the scaled conjugate gradient algorithm. The model was trained and tested using 10 years of meteorological data (1996 to 2006). The authors concluded that the model presented good performance and reasonable prediction accuracy.

Smith et al. 100 modeled several ANNs for the prediction of air temperature 1 to 12-hours ahead in Georgia, USA. The training dataset was collected from 9 meteorological sites between the years 1997 and 2000 (1.25 million patterns). The selection dataset was gathered from 2001 to 2003 (1.25 million patterns) from 13 other locations to determine the best ANN structure. The evaluation dataset corresponded to the years 2004 and 2005 (800 thousand patterns). The models' structure consisted of three layers having only a single hidden layer with 120 neurons organized in three equally sized slabs activated by different functions. The training algorithm was the back-propagation. The input vector, which reached 258 variables, ranged from past previous air temperature, solar radiation, wind speed, humidity, and rainfall. The authors concluded that a 4, 8, and 12-hours horizon displayed unanticipated cooling events, which were the greatest obstacle. Thus, the authors recognized that accurate cloud-cover predictions might aid the associated cooling effect, especially during summer.

Altan Dombaycı and Gölcü [101] developed an MLP model for the estimation of daily mean temperature in Denizli, Turkey. The authors tested different model structures, transfer functions, and training algorithms. The models were trained using measured values between the years 2003 and 2005, and the testing used the measured data from 2006. The best model had 3 input variablesmonth of the year, day of the month, and mean temperature of the previous day $(t-1)$. A single hidden layer with 6 neurons was activated by the hyperbolic tangent sigmoid function. The output was a single variable, and the MLP was trained by the Levenberg-Marquardt algorithm.

\subsubsection{Wet-bulb temperature}

Mittal and Zhang [102] developed two ANNs to predict psychrometric variables in real-time. For the first model five versions were built to determine the number of hidden neurons in each of the three slabs in the hidden layer-15, 20, 25, 30, and 35. Each slab was activated with different transfer functions-Gaussian, Gaussian complement, and hyperbolic tangent functions. All versions had two input variables - dry bulb temperature and relative humidity - and predicted 5 variables - wet-bulb temperature, dew point temperature, enthalpy, humidity ratio, and specific volume. For the second model four versions were built. All models had two input variablesdry bulb temperature and dew point temperature - and wet-bulb temperature, relative humidity, enthalpy, humidity ratio, and specific volume as output variables. The difference was in the number 
of neurons in each of the three slabs-25, 30, 35, and 40. The activation functions in each slab were the same as in the previous models. The training and testing datasets were generated (totaling 12544 sets) from psychrometric equations. From those, $80 \%$ were used to train the models and $20 \%$ to test. The authors considered these models to have reasonable accuracy in real-time use and practical applications such as agricultural drying of food materials and ventilation of farm buildings.

\subsubsection{Dew point temperature}

Shank et al. 103 developed several ANN models for the short-term forecast of dew point temperature from previous values in Georgia, USA. In addition to dew point temperature values ranging from 6 to 30-hours, the input variables were also relative humidity, solar radiation, air temperature, wind speed, and vapor pressure. The hidden layer had 60 neurons that were activated with different functions - Gaussian, Gaussian complement, and hyperbolic tangent. The output variables were $1,4,8$, and 12-hour predictions activated by a logistic function. The training and testing dataset combined three years of measured meteorological data from 40 weather stations. Twenty of those stations were used to test the model. The models were trained using a backpropagation algorithm. Despite being possible to use these models elsewhere, the authors concluded that these models might prove inaccurate as these were not trained with the data of other regions.

Kişi et al. [104 built a GRNN, SOFM, ANFIS with sub-clustering identification (ANFIS-SCI), and an ANFIS with grid partitioning identification (ANFIS-GPI) for the estimation of daily dew point temperature in three locations in South Korea-Daego, Phang, and Ulsan. The input variables and their best combination were mean air temperature, sunshine duration, relative humidity, saturation vapor pressure, and wind speed. The output was a single variable for dew point temperature. The GRNN had a structure of four layers. The first hidden layer had 5 neurons and the following hidden layer had two nodes - one for summation and another for division. The SOFM had four layers with the first hidden layer, the Kohonen layer, with a 5 by 5 matrix. The second hidden layer had 5 nodes. The models were trained using meteorological data from weather stations from those three locations. Data collected between 1985 and 1990 were used to train and test the models (4384 and 2192 patterns, respectively). The models were validated using data measured between 1991 and 1992 (2192 patterns). The results showed that two input variables sufficedmean air temperature and relative humidity. Even though, the models with a greater number of input variables had a slightly better performance, the authors considered that such improvement did not justify the increase of the models' complexity.

\subsubsection{Relative humidity}

Maqsood et al. 105] developed an ensemble of neural networks to forecast 24-hour ahead relative 
humidity, temperature, and wind speed in Saskatchewan, Canada. The ensemble model was built from four networks - an MLP, Elman RNN, RBF, and Hopfield network (HN). The ensemble weights were dynamically determined and proportional to the certainty of the network output. The input variables for each network were 24 values of the weather parameters. A single hidden layer was used in the MLP and RNN with 72 neurons while the RBF network had two hidden layers with 180 neurons. The hidden neurons were activated by a logistic sigmoid function in the MLP model. In the RNN model, the hidden neurons were activated by the hyperbolic tangent function. The RBF network used the Gaussian activation function for the hidden units. Meteorological data, collected at the Regina Airport during 2001, was used for training and testing, and was split into four parts - winter, spring, summer, and fall. Typical days of the dataset-February 26, May 6, August 7, and November 10 - were selected for testing. In comparison to the networks' independent prediction accuracy, the authors concluded that the ensemble model learned and generalized better.

Białobrzewski [106] implemented an MLP model to predict time-series of relative humidity in the city of Olztyn, Poland. The MLP had 10 input variables $-t-1, \cdots, t-10-$ corresponding to 10 past relative humidity values. The interval step was $3 \mathrm{~h}$. A single output variable was chosen. Two hidden layers were used - the first with 3 neurons and the second only 1 neuron. In the first hidden layer the neurons were activated by a non-linear function and the second one by a linear function. The model was trained by a Bayesian regularization back-propagation algorithm. The training and testing data were collected over 100 days, in the year 1988, totaling 823 measurements. From these, 807 were used in the training process and the remaining ones for evaluation.

\subsubsection{Water vapor and cloud liquid water path}

Aires et al. [107] developed two MLP, which used first-guess, to retrieve integrated water vapor content, cloud liquid water path, surface temperature, and microwave surface emissivity over land (ranging between $19 \mathrm{~Hz}$ and $85 \mathrm{~Hz}$ ) from satellite imagery. The first network was used to estimate in clear sky (MLP-1) and the remaining one in cloudy conditions (MLP-2). The MLP-1 model had 17 input variables - 7 satellite observations and first-guess vector (surface temperature, temperature of the lowest layer of the atmosphere, water vapor content, and 7 surface emissivity values). The MLP-2 had the cloud top temperature as additional input. Both models had 30 neurons in a single hidden layer activated using logistic sigmoid function. Both models had the surface temperature, the water vapor content, and the 7 surface emissivity values as the output variables. The MLP-2 model had the liquid water path value as an additional output variable. The models were trained using the back-propagation algorithm. The training dataset was synthesized from a radiative transfer model, a global collection of coincident surface and atmospheric parameters, and emissivity atlases. The authors concluded that the results of the models were encouraging, especially for the 
microwave land surface temperature retrieval as a complement to infra-red estimations in cloudy conditions.

\subsubsection{Cloud classification}

Cazorla et al. [108] developed an imager system with the analysis of an MLP for the estimation and characterization of the sky dome cloud cover in Granada, Spain. A GA was used to optimize the MLP by pruning the unnecessary input variables. The initial input variables of the MLP were the pixels' parameters extracted from the image by using 1 and 9-pixel windows. Over one pixel, the 9-pixel window was centered and the surrounding eight pixels were measured. The parameters were the RGB (red, green, and blue) and gray signals, mean and variance of the RGB and gray values of the surrounding pixels, and the center pixel R/G, R/B, G/R, G/B, B/R, and B/G ratios. Thus, the MLP had 18 input variables, and the output ones were three cloud cover classificationsopaque cloud, thin cloud, and clear sky. A single hidden layer with 18 neurons was used. The hidden and output layers were activated by the logistic sigmoid transfer function. The MLP was trained by the resilient back-propagation algorithm. After the GA optimization process, the MLP input variables were reduced to three - mean of the pixel and the surrounding pixels in the red and blue channels and the variance of the pixel and its surrounding pixels in the red channel. The MLP was tested in a pixel and image-based evaluation. In the first case, the training and testing data were 50 captured images, which resulted in a total of 1000 samples. This set was equally and randomly divided for training and testing. The authors concluded that the use of an MLP permitted the removal of the observers' subjectivity in the cloud classification evaluation and presented good results in light of the measured records. The main weakness of the system was in the circumsolar area of the captured images due to the ultraviolet enhancement effect.

Instead of ground-based estimations, Christodoulou et al. [109] used a satellite imagery-based neural network SOFM to classify cloud images. The data was the thermal infrared channel collected from the METEOSAT7 geostationary satellite, orbiting at $36000 \mathrm{~km}$. A total of 366 samples from 98 images were classified by expert meteorologists into six cloud types-altocumulus-altostratus, cumulonimbus, cirrus-cirrostratus, cumulus-stratocumulus, stratus, and clear conditions. Fifty-two features were then extracted from these samples using nine types of methods - statistical features, spatial gray-level dependence matrices, gray-level difference statistics, neighborhood gray tone difference matrix, statistical feature matrix, laws texture energy measures, fractal dimension texture analysis, and Fourier power spectrum. The SOFM was trained unsupervised - the classification labels were not revealed - with the 366 samples. After the training, each known pattern was assigned to the output nodes of the $12 \times 12$ matrix based on the similarity of the pattern. The Euclidean distance was used. Similar patterns were assigned to the same or surrounding nodes, which had 
lower weight. The SOFM ran three times and the tested results averaged. The SOFM underperformed when compared with $k$-nearest neighbor $(k N N)$ classifier. The authors concluded that these models might facilitate the automated objective interpretation of satellite image classification.

\subsubsection{Fog prediction}

Pasini et al. 110] developed two MLP models to predict (MLP-p) and classify (MLP-c) the fog visibility in a 1 and 2-hour range in Milan, Italy. A model-independent bivariate and pruning analysis was carried out to determine the most important variables. The ten selected input variables were hour of the day (in the form of two variables), visibility, visibility time derivative with respect to the previous hour, sky covering, height of the lowest cloud layer, air temperature, dew point temperature, pressure, and horizontal wind speed. A single hidden layer with 10 neurons activated by a sigmoid function was used. The output variable for MLP-p was visibility in a 1 and 2hour horizon measured in meters. The MLP-c classified the existence, or not, of a fog event at $1000 \mathrm{~m}$ distance visibility threshold. The training method consisted of a moving window of two months updated every hour. According to the authors, this approach allowed better results than traditional train and test approaches. The MLP-p model presented good accuracy with a weighted generalization coefficient $\mathrm{WGC}=0.9706$ and 0.9592 for 1-hour and 2-hour horizons, respectively. The authors compared these results with persistence and climatology scores and their models outperformed them.

Fabbian et al. 111] built an MLP model for the prediction of the occurrence of fog in 3 , 6, 12, and 18-hours horizon in Sydney, Australia. The model had 8 input variables - dry bulb temperature, dew point temperature, wind speed, wind direction, mean sea pressure, cloud cover, surface visibility, and rainfall. Two hidden layers with the number of neurons varying between 3 and 20 nodes, activated by a tan-sigmoid function, were tested. The binary output variable was employed to detect the existence, or not, of fog. The data for training and testing were collected from two databases. The first corresponded to 43 years of 3-hourly observations between 1960 and 2003. The second meteorological dataset referred to the period 1985-2003. The authors concluded that their model had good forecast capability in any of the time horizon predictions studied.

\subsubsection{Thunderstorm prediction}

Manzato [112] described two sound-derived ANNs, in operation since 2001, to estimate the probability and intensity of thunderstorms in the Friuli Venezia Giulia region, Italy. The training data were obtained between 1995 and 2002 and the test data between 2003 and 2004. After initial weather conditions were confirmed and the World Meteorological code 16044 was given, the first model (ANN-c) classified the thunderstorm after three confirmed cloud-to-ground lighting strikes. The ANN-c had two output classes - event with convective activity and event without. From 55 
potential variables, the author selected the proper ones by using a forward selection algorithm. The best ANN-c structure had 9 input variables - activity of the previous case, bulk Richardson number, maximum cap, temperature difference at $500 \mathrm{hPa}$, synoptic hour of the sounding, low-level wind $V$ component, mean relative humidity, mean water vapor $v$ horizontal flux, and standard deviation of radiosonde vertical velocity - a single hidden layer with 6 neurons, and one output variable. The hidden neurons were activated by a logistic function. After confirmation of the event by the previous model, a second model (ANN-r) determined the intensity of the thunderstorm. This model estimated the calculated convective activity in $6 \mathrm{~h}$, which takes into account the number of lightning strikes, rainfall, and maximum wind gust. There were seven input variables: activity of the previous case, mean buoyancy acceleration of the lowest $250 \mathrm{hPa}$, convective inhibition, synoptic hour of the sounding, mean relative humidity, maximum buoyancy, and wind shear in the lowest $3 \mathrm{~km}$. The activation function was linear. The author concluded that the results can be strongly related to the region's orography, thus further testing in other regions is required.

Wang et al. [113] developed an MLP optimized by a cuckoo search algorithm to forecast lightning strikes from sounding-derived indices in Nanjing, China. The sound-derived indices were preprocessed using singular spectrum analysis. Four input variables were determined from several indices - convective available potential energy, $K$ index, Jefferson index, and severe weather threat index. The hidden layer had 2 neurons. The output was a single variable that represented fair weather (0) and thunderstorms (1) classes. Both hidden and output layers were activated by a sigmoid function. The training data were obtained from measured data between 2007-2010 and the testing data between 2011-2012. After comparison with other models, the authors stated that the proposed approach was the most efficient and a useful tool to predict lightning.

\subsection{Hydrologic-related}

The forecast of hydrologic resources and processes allows to adequately manage water resources and predict the potential of renewable energy production from the river flows, waves, and tides. These allow to plan and to manage the renewable energy generation and to prevent hazardous events to the built environment from extreme weather conditions, such as the ones that may result from flash floods, storms (fall of snow, hail, and precipitation), sea rise, and droughts. From a sustainable environment perspective, the water quality monitoring and estimation is fundamental to determine

the amount of available drinking water (lake level, groundwater level, and reservoir inflow) and to prevent undrinkable water events (salinity and sediments concentration). Also, the proliferation of micro-organisms (due to water temperature variation) that disturb the watercourses ecosystem, which, ultimately, may affect the human health when consumed untreated, can be avoided.

The hydrological forecasting is distinguished by the dynamics of water patterns and complex- 
ity. As the physical models are laborious, statistical models and artificial intelligence models are showing potential and becoming promising solutions. These seek to find relations between the input and desired output variables, independently of knowing the physical process that describes the phenomena. Contrary to the statistical models, artificial intelligence is particularly suitable for hydrologic forecasting, as they are able to deal with the non-stationarity, non-linearity, and data noise in the forecast problems. Therefore, the quantity of information in the modeling process is important in order to have an accurate model. Valipour [114] studied the impact of the time length of the training dataset and observed that, in temperate and semi-arid climates, 60 data observations were sufficient for the model to predict next year rainfall forecasting. However, in arid and humid climates, the accuracy increased at the same rate that the size of the observation data increased.

The neural networks, and these have been applied in hydrology forecast since the 1990s. As an example, some authors focused on precipitation forecasting [115], rainfall-runoff prediction [116122], river flow estimation [123 125], flood prediction [126], reservoir inflow [127], and river sediments estimation [128]. Due to the non-linearity of the hydrological forecasts, Valipour [129] used a non-linear autoregressive neural network (NARNN), non-linear input-output, and NARNN with exogenous input. However, according to the author, the number of hidden neurons needed to be optimized in order to improve the network accuracy to detect drought and wet years. The selection of input variables is also a critical part of the modeling process and for that, Taormina and Chau [130] developed an input variable selection scheme with binary-coded discrete fully informed particle swarm optimization (FIPS) and ELM model. The results of the proposed model have proven to be particularly accurate in rainfall-runoff applications. The same authors [131] also trained the neural network using a cross-validation multi-objective optimization using a FIPS algorithm, as the use of global search methods in the training process of the learning algorithm is important to prevent the model from being stuck in local optima. Another approach consists in pre-determining the impact in the forecast variable. For instance, Tehrany et al. [132] implemented a weightsof-evidence model to firstly determine the impact of classes of input variables on an SVM model to predict flood occurrences. The authors tested several kernels (linear, polynomial, radial basis function, and sigmoid) and found that the radial basis function kernel was the most suitable. The hybridization of the traditional methods has enhanced the predictability of the models and these are now capable of better capturing the hydrological patterns [133-135].

Other literature reviews on water resources, hydrologic processes, and applied methods may be found in refs. [35, 134 145]. This subsection covers research works on precipitation, rainfall-runoff process, hail, snowfall, snow cover, snow depth and snow water equivalent, evapotranspiration, drought, streamflow, flood, waves, tides, groundwater level, lake level, reservoir inflow, sediments, 
salinity, and water temperature. Tables 8 and 9 summarize these analyzed works.

\subsubsection{Precipitation}

Toth et al. [146] compared an ANN, a linear stochastic autoregressive moving-average (ARMA), and a $k \mathrm{NN}$ for $1 \mathrm{~h}$ to $6 \mathrm{~h}$ short-term rainfall forecast in the Apennines mountains, Italy. The ANN had 3 input variables from $t$ to $t-2$ and a single hidden layer with 3 neurons. The number of output variables varied between $t+1$ to $t+6$. The model was trained using the Levenberg-Marquardt algorithm. For the same model, two variations were created during training. In the first training, $\mathrm{ANN}_{s}$, the measured data was divided into two parts, with the training set having two-thirds of the sample. In the second training, $\mathrm{ANN}_{a}$, the model was adaptive and trained in an online fashion. The dataset comprised hourly rainfall depths at 12 rain gauges in the basin of the site between 1992 and 1996. The authors concluded that the $\mathrm{ANN}_{s}$ was more suitable for longer lead-time periods predictions and that neural networks underperformed in low rainfall scenarios.

Hong et al. [147] developed a satellite-based rainfall estimation algorithm by extracting cloud infrared features $(10.7 \mu \mathrm{m})$ imagery with a resolution of $0.04^{\circ}$ every $30 \mathrm{~min}$ in Las Vegas, Nevada, USA. The algorithm identified cloud patches, extracted cloud features, clustered the cloud patches, and calibrated cloud-top temperature and rainfall for the classification of clouds. The classification model was a SOFM with 23 input variables - cloud patch coldness, geometry, and five brightness temperature texture features. The training of the SOFM was carried out in two stages: in the first stage, an unsupervised clustering was carried out that resulted in 400 groups; in the second stage, an unsupervised clustering was carried out, which resulted in 400 groups. In the second stage, the rainfall was assigned to the classified groups, thus adding an extra linear output layer. The authors concluded that they successfully dealt with the problem of previous works, which only considered local features, when incorporating cloud patch scales.

\subsubsection{Rainfall-runoff}

Sudheer et al. [148] developed an RBF model for the rainfall-runoff estimation of the Baitarani river basin in India, with a statistical pre-processing to determine the appropriate input variables vector. The statistical analysis using a cross-correlation and autocorrelation function, allowed to find the lags of data that had a significant influence on the predicted flow. Nine input variables were determined for the input vector-a 4-day lag runoff and a 5-day lag rainfall. The model was trained using the minimum description length algorithm to determine the significant basis functions and connection weights. The data was collected over 23 years, between 1972 to 1994, the daily values of rainfall and runoff for the monsoon season. When compared with ARMA and MLR, the RBF outperformed all. The authors affirmed that the statistical pre-processing allowed to reduce the computation time by using smaller networks and it also reduced the model's development effort. 
Tokar and Markus [149] developed three ANN models for the estimation of the daily rainfallrunoff in the basins of the Fraser river in Colorado $\left(\mathrm{ANN}_{f}\right)$, Raccoon Creek in Iowa $\left(\mathrm{ANN}_{r}\right)$, and Little Patuxent river in Maryland $\left(\mathrm{ANN}_{l}\right)$, USA. The $\mathrm{ANN}_{f}$ had five input variables - streamflow at time $t-1$, precipitation at time $t-1$, snow water equivalent at time $t-1$ and $t-2$, and air temperature at time $t-1$. The time step was one month. A single layer with two neurons was activated by a sigmoid transfer function. The training and testing datasets comprised the measured data from the Fraser river watershed in the periods between 1951-83 and 1987-93. The training dataset corresponded to the months of May, June, and July for the years 1951 to 1980. The remaining years were used for testing. The $\mathrm{ANN}_{r}$ had 5 input variables - precipitation at time $t-1$, $t-2$, and $t-3$, air temperature at time $t$, and streamflow at time $t-1$. The time step was in days. The hyperbolic tangent activation function was used for the hidden layer with 24 neurons. The calibration dataset was obtained from measurements between 1978 and $1993 . \mathrm{ANN}_{l}$ had 3 input variables - precipitation at time $t$ and $t-1$, and air temperature at time $t$. A single hidden layer with 10 neurons activated by a hyperbolic tangent function was implemented. The training dataset was obtained from measured data in 1979, 1980, and 1984. The testing dataset was collected from 1989, 1991, and 1992. All models were trained using the back-propagation algorithm. Not only did the authors concluded that the models were more accurate than conceptual models, but they also stated that those models allowed a systematic approach and shortened the time spent on training.

\subsubsection{Hail}

Marzban and Witt [150] developed two Bayesian neural network (BNN) models for the prediction and classification of severe hail in the USA. The input vector had the same nine variables for both models - cell-based vertically integrated liquid, severe-hail index, storm-top divergence, mid-altitude rotational velocity, height of the wet-bulb zero, height of the melting level, vertically integrated wet-bulb temperature, wind speed at the equilibrium level, and storm-relative flow at $-20^{\circ} \mathrm{C}$ level. The first model $\left(\mathrm{BNN}_{r}\right)$ determined the hail size and therefore had only one output variable. A single hidden layer was employed and activated by a logistic function. The second model $\left(\mathrm{BNN}_{c}\right)$ classified the hail into three classes - coin, golfball, and baseball sizes. The output layer had three variables, each corresponding to each class with the probability of occurrence of that hail size. The number of hidden neurons in both models was determined via bootstrapping with four sets. The training and testing of both models comprised 386 samples (250 for training and the remaining for testing) collected from 81 storm cases in different regions of the USA. The $\mathrm{BNN}_{c}$ presented high quality forecasts in term of reliability, refinement, and discrimination diagrams, with the exception of the second class, which displayed no statistically significant skill. According to the authors, this was due to the difficulty in discriminating non-extreme events. 


\subsubsection{Snowfall}

Roebber et al. [151] developed a 10-member ensemble of MLPs to classify snowfall ratio in the USA. Seven input variables were used-month index, low to mid-level temperature and relative humidity, mid to upper-level temperature, upper-level relative humidity, mid-level relative humidity, and external compaction. The ensemble predicted three classes - heavy, average, and light. Two types of neural networks were used: the first type was a three-layered MLP that corresponded to half of the ensemble members, with a hidden layer of 40 neurons; the second type was a four-layered MLP with two hidden layers having seven neurons in the first hidden layer and four in the second layer. The hidden neurons in all of the networks were activated by a hyperbolic tangent function. The output layer in all of the networks had three variables, each for every class, and these were activated by a softmax activation function. The modeling data from 28 radiosonde sites were extracted from the National Climatic Data Center/Forecast Systems Laboratory and the new-snow amounts were obtained from the United States Air Force DATSAV2 Surface Climatic database. The total dataset comprised 1650 events ranging from 1973 to 1994 . Sixty percent of the data were used for training, $20 \%$ for cross-validation, and $20 \%$ for testing. When compared to other approaches, the model significantly outperformed in any of the three snowfall ratio classes.

\subsubsection{Snow cover}

Simpson and McIntire [152 developed an FNN and a RNN for the classification of areal extent of snow cover from satellite images. The FNN classifies individual images and the RNN classifies sequence of images. Images were preprocessed to ensure data quality prior to texture modeling and formation of the input vectors. For the FNN model, the input variables were from the Advanced Very High Resolution Radiometer channel 2 albedo, channel 4 brightness temperature, channel 3 data calibrated radiance, ratio between channel 2 and channel 1 albedos, homogeneity texture of channel 2 albedo, and, finally, entropy texture of channel 2 albedo. A single hidden layer was used with 10 neurons. Three output variables for each class - clear, cloud, and snow-defined the multiband percentage composition of the map. Both the hidden layer and output layer were activated by the sigmoid function. For the RNN model, there were nine input variables - spectral and texture information from the current image (ratio between channel 2 and channel 1 albedo was substituted by the homogeneity texture difference of the current and previous image) and the output result of the previous image $t-1$ values. The back-propagation algorithm was used for training in both models. The training set was created from 20 images covering the western half of the USA. A total of 3430 samples were classified for training the FNN and 2457 for the RNN model. The validation of the models was carried out by ground-based information via snow telemetry data. The authors noted that the classification bias error was much smaller for the RNN 
than the FNN due to cloud shadow and cloud edge pixels and that post-processing was able to reduce those errors.

\subsubsection{Snow depth and snow water equivalent}

Tedesco et al. 153. developed an MLP model for the retrieval of snow depth and snow water equivalent by inverting special sensor microwave imager brightness temperatures in Finland. Four input variables were used $-19 \mathrm{GHz}$ and $37 \mathrm{GHz}$ vertical and horizontal brightness temperatures. A single hidden layer was used but the number of hidden neurons depended on each of the 12 test sites, being these activated by a sigmoid transfer function. The output variable was the snow depth or the snow water equivalent. The MLP training was carried out using simulated or ground measured brightness temperatures and it was tested with a dataset of ground measurements over Finland gathered between 1997 and 1999. When trained with measured data, the model presented best performance than when using simulation data; in both cases, still better than the spectral polarization difference algorithm, HUT model-based iterative inversion, or Chang's algorithm. The authors concluded that the model was able to retrieve the spatial or temporal variations of the unknown data, especially when trained with on test sites data.

\subsubsection{Evapotranspiration}

Kumar et al. 154] compared several ANN model architectures to determine the best one to estimate the evapotranspiration in Davis, California, USA. The best model had six input variablessolar radiation, maximum and minimum temperature, maximum and minimum relative humidity, and wind speed. The only hidden layer had 4 neurons activated by a sigmoid function. The output variable was the evapotranspiration value. The model was trained using the standard back-propagation algorithm. The climatic data measured at the Davis California Irrigation Management Information System station for the period January 1, 1990 to June 30, 2000 were used for training and testing. The evapotranspiration values for modeling were calculated using the Penman-Monteith method. A second set of data were also used in the modeling process with daily lysimeter measurements of grass evapotranspiration from January 1, 1960 to December 31, 1963. These results were better than the estimations given by the Penman-Monteith method. The authors then concluded that the ANN was a better model for estimating evapotranspiration for the Davis site.

\subsubsection{Drought severity index}

Kim and Valdés [155] developed an MLP combined with dyadic wavelet transforms to forecast time-series of drought severity index in the Conchos river basin in Mexico. Different model architectures with different input variables and neurons in a single hidden layer were tested to 
determine which had the best performance. The output variable was the Palmer drought severity index. Four models were used to forecast $t+1\left(\mathrm{MLP}_{1}\right), t+3\left(\mathrm{MLP}_{3}\right), t+6\left(\mathrm{MLP}_{6}\right)$, and $t+12$ $\left(\mathrm{MLP}_{12}\right)$ months ahead. The best models for $\mathrm{MLP}_{1}$ and $\mathrm{MLP}_{12}$ had three input variables and 3 hidden neurons and for $\mathrm{MLP}_{3}$ and $\mathrm{MLP}_{6}$ there were four input variables and four hidden neurons. The models were trained using the back-propagation algorithm. The calculated data were used for training (years ranging from 1955 to 1990) and validation (between 1991 and 2000). When compared with a conventional $\mathrm{ANN}$, the $\mathrm{MLP}_{1}, \mathrm{MLP}_{3}$, and $\mathrm{MLP}_{6}$ displayed better accuracy, but the $\mathrm{MLP}_{12}$ underperformed. When compared to traditional climatology models, the MLP models performed better between $7.3 \%$ and $60 \%$.

\subsubsection{River flow}

Nayak et al. [156] developed an ANFIS model to forecast river flow time-series in the Baitarani river, Orissa state, India. The input variables were the antecedent river flows $t-1$ and $t-2$. The model was trained with four if-then rules that used the fuzzy intersection operator. The output variable was the river flow. The model was trained using transformed flow series for the period 1972-1989 and validated with data from the period 1990-1995, and by using cross-validation technique with four sets. When compared with conventional ANNs, the ANFIS had a comparable performance and outperformed the ARMA model. The ANFIS also presented better errors distribution and simpler structure.

\subsubsection{Flood}

Chau [157] developed an MLP model for the prediction of the water level of the Shing Mun river in Hong Kong, China. A single input variable was used with the current day water level. The hidden layer had 3 neurons. The output variable predicted one of the time ahead values$t+1\left(\mathrm{MLP}_{1}\right), t+2\left(\mathrm{MLP}_{2}\right)$, or $t+7\left(\mathrm{MLP}_{7}\right)$. The time step was in days. Instead of using the back-propagation algorithm - according to the authors, the algorithm converges slowly and can be easily entrapped in a local minimum - the model was trained by a particle swarm optimization method. The modeling dataset comprised measurements from the river tributaries of Fo Tan and Tin Sam for three years starting in 1999. The two first years were used for training and the last one for testing. When compared with the same model trained using back-propagation, the proposed approach presented better results.

\subsubsection{Wave height}

Deo et al. [158 implemented a three-layered MLP model for the forecast of wave height and average period in the Arabian sea in the west coast of India. The model had wind data as input and wave data as output. The model was trained using a cascade correlation and conjugate gradient 
algorithms. Three locations were tested; in the first one, 3-hourly values of wave height and average zero cross period data were collected from a rider buoy offshore of Karwar, India, at $16 \mathrm{~m}$ deep water. The wind speed was measured at a shore-based station from March to July 1988 and from December 1988 to May 1989. This comprised a total of 900 sets of data. The model for this location had two input variables - wind speed at time $t$ and $t-1$. The hidden layer had 4 neurons. The authors justify the low prediction accuracy of the model due to different wave and wind measuring places. In the second location, the wave and wind data were measured in the same place and at a lower water depth of $75 \mathrm{~m}$. A dataset of 140 patterns was collected and $20 \%$ were used for testing. In this case, the model increased its accuracy. In the last location, weekly mean wind speed and significant wave heights measured by a radar altimeter via the TOPEX satellite were collected from some locations off-shore the coast of India. The data covered 42 months from October 1992 to March 1996. The model had 4 input variables - weekly wind speeds in a month. The output had 4 variables - weekly wave height in a month. Authors concluded that despite satisfactory results, short-term predictions might be difficult due to the rapid variations of wind measurements.

\subsubsection{Tide level}

Lee [159] developed an MLP model for the prediction of long-term tides at Taichung Harbor in Taiwan. The three-layered MLP had 7 hidden neurons activated by the sigmoid function. Five input variables were defined - luni-solar semi-diurnal, principal solar, larger lunar elliptic, luni-solar diurnal, and principal lunar diurnal tidal constituents. The output was a single variable for the tide level. The back-propagation training algorithm was used. The modeling dataset was collected from hourly tide levels measurements during the years 1995 to 1998, and the training set corresponded to 15 days from 12 to 26 of April 1996. The authors concluded that the results were satisfactory.

\subsubsection{Groundwater level}

Daliakopoulos et al. [160] developed and compared seven ANN models to forecast groundwater level up to 18-month ahead in Messara Valley in Crete, Greece. The input layer had 20 variablestime lag $t$ to $t-4$ for precipitation, temperature, streamflow, and groundwater level. The output was the well level at time step $t+1$. The time step was in months. The model that presented the best performance was an MLP trained by the Levenberg-Marquardt algorithm. A single hidden layer was used with 3 neurons. The modeling dataset consisted of measured hydrologic and meteorological data ranging from 1988 to 2002. The training data corresponded to the years between 1988 and 1998, the calibration data comprised the years 1998 to 2000, and the remaining data were used for testing. In addition to 1-month ahead, the models were also analyzed for 6, 12, and 18-month ahead. According to the authors, the MLP displayed the most accurate predictions of all seven models. 


\subsubsection{Lake level}

Khan and Coulibaly [161] compared SVM and MLP models to predict water level up to 12month ahead in Erie Lake, Great Lakes, USA. The input vector for both models was the past 2-month water level values and the corresponding months identified in 12 binary variables corresponding to the month the water level input was for. A single output variable was used to predict $t+1$ to $t+12$ water level ahead. The SVM used the radial basis kernel function and the MLP had five hidden neurons and a single output variable activated by the hyperbolic tangent function. The training algorithm was the back-propagation for the MLP model. The training of the models comprised data from 1918 to 1989 and the testing data from 1990 to 2001. The authors noted that the SVM presented the best accuracy and required the lowest number of parameters.

\subsubsection{Reservoir inflow}

Coulibaly et al. [162] implemented an MLP model for real-time forecasting of reservoir inflow in Chute-du-Diable watershed, Quebec, Canada. An early stopped training approach was used, which took advantage of both the Levenberg-Marquardt algorithm and cross-validation technique. The input had 14 variables - water inflow at time $t-1$, maximum, minimum, and mean temperature at time $t$, and precipitation and snowmelt at time $t-4$ to $t$. The number of neurons in the single hidden layer was 24. The output was a single variable for 1 to 7 -days ahead forecasting. The modeling dataset consisted of 32 years of daily natural inflows, precipitation, estimated snowmelt, and daily temperature ranging from 1964 to 1995. The years from 1964 to 1980 were used for training and data from 1981 to 1992 for testing. When compared with conventional models, the proposed model had better performance for 2 to 7 -days ahead. However, the ARMA with an exogenous inputs model was the best approach for 1-day ahead. The authors concluded that the MLP with early stopped training provided better and reliable generalization performance than neural networks with back-propagation training algorithms and substantially better predictions than conventional models.

\subsubsection{Sediments concentration}

Nagy et al. 163] developed an MLP model to predict sediment load concentration in several rivers in the USA. Six input variables were defined - tractive shear stress, suspension parameter, water depth ratio, Froude number, Reynolds number, and stream width ratio. A single hidden layer with 12 neurons activated by a sigmoid function was used. The output variable was the sediment concentration. The MLP was modeled with two datasets; the first one was a group of 161 observations from the rivers Niobrara, Middle Loup, Hii, and Small Streams. Two equal sized datasets were randomly created for training and testing. The second modeling dataset was comprised of 486 observations for the testing phase, which were collected from the Rio Grande, Mississippi, and 
Sacramento rivers. When authors compared their results with conventional models found in literature, the MLP only displayed good accuracy on datasets where observations had similar sediment concentrations to the training dataset. Otherwise, it had similar or better performance.

\subsection{1\%. Salinity}

Huang and Foo [164 implemented an MLP model for the estimation of salinity in the Apalachicola river, Florida, USA. The model had three layers. Models with different number of hidden neurons were tested. The final model had 16 hidden neurons activated by a logistic sigmoid function. The input variables were tide level, wind speed and direction, and river flow. The output was the river salinity concentration. The model was trained by the conjugate descent algorithm. The modeling dataset consisted of hourly salinity time-series measured at a station in the lower portion of the river, river flow from USGS data, and tidal data from National Ocean Survey. Two datasets were built for training and testing for measured data in July 1993. The authors considered the model to be a cost-effective and easy-to-use tool.

\subsubsection{Water temperature}

Sahoo et al. [165] developed a four-layered MLP model to forecast 3-day time lag of stream water temperature in Incline Creek, Glenbrook Creek, Upper Truckee river, and Trout Creek streams at Lake Tahoe, USA. Six input variables were used-air temperatures and short-wave radiations at time $t$ to $t-3$. The output was the water temperature variable. The model was trained using a micro-GA. Daily time series data from January 1999 to the end of September 2002 for the four streams were used for training (2000-2001), validation (1999), and testing (2002). The proposed model presented higher prediction accuracy than a three-layered MLP and an RBF model, also tested by the authors.

\subsection{Geologic-related}

The forecasting and estimation of geologic-related variables is important to adequately plan and design the built environment, to prevent hazardous events, and to generate renewable energy. Knowing the soil types and how these are distributed over the land helps to quantify the amount of available biomass that can be used to produce energy and by determining the organic matter helps identifying the most suitable lands for agriculture. Also, knowing the variation of ground temperature according to the depth assists to determine the potential of using geothermal energy. Besides renewable energy-related estimations, a sustainable built environment is also dependent of the safety of its built structures. This obliges planners and decision-makers to choose the best places for construction, which also depends on estimating the susceptibility of landslides and liquefaction due to earthquakes (estimate and classify according to their magnitude), soil subsurface stability, 
and the future erosion of soils, as well as other aspects of soil mechanics. Therefore, a sustainable built environment is dependent of a comprehensive analysis and estimation of the resources and land use.

Traditional techniques involve field and laboratory tests that are costly, time consuming, and sometimes destructive of the sample analyzed. For these reasons, indirect estimation methods such as neural networks gain interest. In the 1990s, the use of neural networks to predict geologic phenomena and soil properties raised interest in the research community due to their fast implementation, robustness, and accuracy. Several approaches laid the background to future contributions, such as in earthquake prediction [166], soil liquefaction [167], soil structure estimation [168], soil mechanics [169, 170], hydraulic properties [171], and soil water retention [172]. However, in the last three years, researchers' attention has fallen upon the determination of the best model types and adequate input variables for the prediction of landslide susceptibility [173-177], specifically in pre-evaluating the input variables [173, 174, determining the accuracy performance of each model type [175, 176], and comparing the alternative models against common neural networks [177]. The use of optimization algorithms with global search capabilities or the hybridization of the learning models are not so commonly used as in the atmospheric or hydrologic fields. However, some papers may be found on the prediction of geologic-related variables [178-180]. As an example, Gordan et al. 180 used particle swarm intelligence to optimize an ANN to estimate the seismic slope stability. The reason for the reduced use of enhanced approaches may be found in the stability and linearity of most of the geologic-related problems. Past literature reviews, on the application of neural networks, cover rock parameters estimation [181], geotechnical engineering [182, 183], rock engineering [184, and earthquake prediction [185].

This subsection covers landslide susceptibility mapping, earthquake classification, liquefaction prediction, erosion estimation, soil classification, structure, soil mechanics, soil organic matter and carbon content, ground temperature, thermal conductivity and resistivity, electric resistivity, and hydraulic properties. Tables 10 and 11 summarize the analyzed works.

\subsubsection{Landslide susceptibility}

Lee et al. [186] developed an ANN to determine the weights of seven landslide parameters used in a probabilistic method. A weighting method was then used to produce landslide susceptibility maps from the Yongin area, Korea. The ANN used topographic (slope and vertical curvature), soil (texture, thickness, and drainage), and vegetation (trunk diameter and wood age) as input variables. A single hidden layer was used with 15 neurons activated by a sigmoid function. The output layer had two variables to classify the existence or not of a landslide. The model was trained using the back-propagation algorithm. The information from topographic, soil, and wood thematic 
maps, as well aerial photograph and field surveys of landslides, were used to build the modeling datasets. The training dataset was made up of 400 random points. The process was repeated 10 times with random locations and the results were averaged for each landslide factor. These were then normalized, according to the topography curvature, and used to calculate the landslide susceptibility index of the region map. The maps were finally compared and verified. The model presented satisfactory agreement with the observed data.

Yesilnacar and Topal [187] built an MLP model to determine a landslide susceptibility map in Hendek region, Turkey. The input layer had 19 variables - fault density, distance to fault, elevation, slope, slope length, profile curvature, plan curvature, distance to roads, road density, drainage density, distance to drainage, land cover, distance to ridges, geology, surface area ratio, topographic wetness index, stream power index, sub-watershed basins, and aspect. Thirteen hidden neurons, in a single layer, were activated by a sigmoid function. The output variable classified the input variables in very low, low, high, and very high landslide susceptibility. The training was carried out by the back-propagation algorithm. The training dataset consisted of 12036 samples (65\% of the total data). The validation and testing datasets were $2407(13 \%)$ and $4000(22 \%)$ samples, respectively. The MLP showed better accuracy than the logistic regression model, also developed by the authors, especially in high and very high zones. The authors concluded that the MLP was more realistic, as it was more in agreement with field observations.

\subsubsection{Earthquake classification}

Adeli and Panakkat [188] implemented a PNN for the prediction of earthquake magnitude in southern California, USA. Eight input variables were used - the time elapsed during a particular number of seismic events in the previous month, the slope and the mean square deviation of the Gutenberg-Richter inverse power law curve, the average magnitude, the difference between observed maximum magnitude and the expected from the Gutenberg-Richter relationship, the rate of square root of seismic energy, the mean time between characteristic events, and the coefficient of variation of the mean time. The PNN had two hidden layers - the pattern and summation layers. The first hidden layer had as many nodes as input vectors and the second hidden layer had the number of classes as neurons - in this case seven classes of earthquake magnitude with 0.5 Richter range. The Gaussian function was used as a window function, where each node computed the Euclidean distance between the input vector and the training input vector. The training dataset was made up of historical earthquakes between 1st January 1950 and 13th December 1990 (997 input vectors). For the testing dataset, the historical record between 1st January 1990 and 24th September 2005 was used. The model only showed good accuracy for earthquakes of magnitude between 4.5 and 6.0. Lastly, the authors state that in a preceding work [189], an RNN presented better accuracy 
for earthquakes with a magnitude higher than 6.0 Richter.

Scarpetta et al. [190] implemented an MLP model for the classification of seismic signals at Mount Vesuvius Volcano, Italy. The method was helpful as it discriminated between natural and artificial signals. The input variables were extracted from signal spectral features and waveform that were obtained using linear prediction coding and waveform parameterization techniques. The single hidden layer was activated by a hyperbolic tangent function and the output variable by a logistic function. The output variable classified the signal as earthquake or not. Two alternative models were tested with different training algorithms - quasi-Newton algorithm (MLP-qN) and scaled conjugate gradient algorithm (MLP-SCG). The training and test datasets consisted of recorded data from four stations totaling 550 and 331 samples, respectively. Despite similar performance, the MLP-qN was significantly more demanding computationally. The approach showed good results in both artificial false events (quarry and sea-side explosions) and natural false events (thunder).

\subsubsection{Liquefaction prediction}

Goh [191] developed two PNNs for the estimation of the seismic liquefaction potential from cone penetration test data (PNN-c) and shear wave velocity data (PNN-v). The models had four layers. The PNN-c input layer had 6 variables - earthquake magnitude, the peak acceleration at the ground surface, the total vertical overburden stress, the effective vertical overburden stress, the measured cone perforation test tip resistance, and the mean grain size. The PNN-v also had 6 input variables but instead of the last two variables, it had the measured shear wave velocity and the soil type number as input. In both models, the pattern layer had the number nodes equal to the training samples. The summation layer had two neurons. The binary output classified the input vector as occurrence or non-occurrence of liquefaction, and a GA was used for training. For PNN-c and PNN-v, the training consisted of two thirds of 170 and 186 samples, respectively. The remaining one third was used for testing. The author stated that these significantly outperformed conventional methods.

Pal [192] implemented two SVM models for the prediction of earthquake liquefaction potential from standard penetration test data (SVM-s) and cone penetration test data (SVM-c). From a combination of several input variables, SVM-s had seven inputs selected - standard penetration test value, mean grain size, total stress, effective stress, earthquake magnitude, fines content, and normalized horizontal acceleration at ground surface. In the case of SVM-c, five input variables were chosen - cone resistance, mean grain size, effective stress, earthquake magnitude, and normalized horizontal acceleration at ground surface. The models' output was the classification of occurrence and non-occurrence of liquefaction. For SVM-s, the modeling datasets were collected from previous 
works and consisted of 59 and 26 records (training and testing, respectively) obtained between the years 1891 and 1980 in different world regions. Similarly, for SVM-c, the training and testing datasets were obtained between 1964 and 1983 and consisted of 74 and 35 records, respectively. The authors stated that SVM models presented better results than preceding studies.

\subsubsection{Erosion estimation}

Licznar and Nearing [193] developed an FNN model for the prediction of soil erosion in eight locations in eastern USA. Several alternative model structures were tested and the one with best results had 10 input variables - precipitation, duration of precipitation, canopy cover, inter-rill cover, effective hydraulic conductivity, adjusted inter-rill soil erodibility, adjusted baseline rill erodibility, number of days since last disturbance, slope steepness, and slope length. A single hidden layer with 10 neurons activated by a tan-sigmoid function was employed. The output layer had two variables - soil loss and runoff. The training algorithm was the Levenberg-Marquardt algorithm. The training ( $50 \%$ of the total data), validation (25\%), and testing (25\%) datasets were measured in eight locations in eastern USA. An alternative model with just a single output for soil loss and 40 hidden neurons showed lesser accuracy. Despite good accuracy, the authors affirm that a major limitation of the widespread use of these models was the lack of physical concepts and relations, which may lead to the abnormal understanding of the results due to the complex functioning of the erosional system.

\subsubsection{Soil classification}

Chang and Islam [194] developed a SOFM and an MLP models to infer soil texture classes in a dry-down process using remotely sensed data and soil properties in Little Washita watershed, Oklahoma, USA. Two input vectors were tested-brightness temperature $\left(\mathrm{SOFM}_{b 3}\right.$ and $\left.\mathrm{MLP}_{b 3}\right)$ or soil moisture $\left(\mathrm{SOFM}_{m 3}\right.$ and $\left.\mathrm{MLP}_{m 3}\right)$ - for both models to classify soil types. The SOFM models classified the soils into three groups - coarse, medium, and fine soil-as function of ratio of sand to percent of clay. The MLP models had a single hidden layer, which was activated by a binary sigmoid function. The output layer classified the input vector into the same three classes as SOFM models. The MLP models were trained using the Levenberg-Marquardt algorithm. The authors also tested the MLP to classify data into six groups - sand, loamy fine sand, fine sandy loam, loam, silt loam, and silty clay loam/clay loam. The output was an integer corresponding to each class. The authors concluded that the SOFM models presented reasonable accuracy for the cases where soil properties were not available; however, the MLP models had better results. These models only work well if no other physical attribute is present in neighboring grid points, such as rainfall variability, lateral flow, topography, etc. 
Zhao et al. 195] developed an ANN model to generate high-resolution maps of soil texture distribution (clay, silt, and sand contents) from soil attributes in Black Brook watershed, New Brunswick, Canada. The model had 6 input variables - clay content, sand content, soil terrain factor, drainage, sediment delivery ratio, and vertical slope position. A single hidden layer was used with 25 neurons activated by a sigmoid function. The output was the clay and sand contents. The silt content was calculated by subtracting the predicted values. The Levenberg-Marquardt algorithm was used for training. The training (14 196 samples) and testing (12 957 samples) datasets were gathered from 46 polygons of detailed quantitative soil texture data. These were re-sampled into a grid with $10 \mathrm{~m}$ resolution. The model presented a good predictive capability according to the authors.

\subsubsection{Subsurface cavities}

Elawadi et al. [196] implemented an approach to determine the depth and radius of subsurface cavities at the Medford cave site, Florida, USA. The depth to the cavity center was estimated using an MLP model, the horizontal location was determined from picking the minimum gravity anomaly, and the radius of the cavity was calculated from density difference between host rock and cavity filling materials. The input layer had 21 variables of gravity measurements, 5 neurons in the hidden layer, and a single variable in the output layer. The training set of 15 samples was synthetically generated with different depths ranging from $1 \mathrm{~m}$ to $8 \mathrm{~m}$. The model was tested with 14 samples of synthetic data for cylindrical and spherical cavities. The back-propagation algorithm was used, and a field test was carried out at Medford cave site. The authors noticed that data agreed well with the drilling tests thus concluded that it provided fast and robust determination in working field scenarios.

\subsubsection{Soil mechanics}

Sonmez et al. [197] developed an MLP model to predict the elastic modulus of intact rock. The input variables were uniaxial compressive strength and unit weight. A single hidden layer was used with 2 neurons, which were activated by a sigmoid function. The output was the elastic modulus of intact rock. The model was trained using the back-propagation algorithm using 487 randomly selected samples of a total of 609 from more than 35 rock types. The remaining subset was used for testing. The dataset was compiled from published data in the literature and laboratory tests on greywacke and agglomerate core samples. The results allowed building a prediction chart of elastic modulus of intact rocks, which showed a strong prediction capability and could be used for practical purposes.

Singh et al. 198 implemented an ANFIS model for the prediction of the deformation modulus of rocks, also known as Young's modulus. Three input variables were used-point load, density, 
and water absorption. A Gaussian membership function and three fuzzy if-then rules were used. The output was a single variable to determine the deformation modulus. The model was trained using the back-propagation algorithm with a dataset of 85 samples and it was tested using 10 samples. The authors stated that ANFIS showed good predictive capability using vague and imprecise information.

Yilmaz and Kaynar [199] compared an MLP, an RBF, and an ANFIS for the prediction of the swell percent of soil. The input variables were the liquid limit, activity, and cation exchange capacity. The MLP and RBF models had a single hidden layer. The MLP had 2 neurons and the RBF had 16 neurons. Both models had their layers activated by tan-sigmoid activation function. The MLP was trained by the back-propagation algorithm, while RBF was optimized using a least mean square algorithm. The ANFIS had 5 layers and was trained using a combination of gradient descent and least-squares method. The training (60\%), testing (20\%), and verification (20\%) datasets were built from 215 soil test samples. The authors concluded that RBF exhibited the most reliable predictions and the main advantage was a greater degree of robustness and fault tolerance in comparison to traditional statistical models.

Lee et al. 200] developed ANN models and a hyperbolic formulation for the prediction of unsaturated soil shear strength. The ANN would determine the apparent cohesion parameter of the saturated soils shear strength formulation, which also includes two other parameters - the internal friction angle and the effective soil cohesion. Four ANN models were tested. The first model $\left(\mathrm{ANN}_{I}\right)$ had six input variables - sand fraction, clay and silt fraction, void ratio, compacted water content, cohesion, and friction angle. The remaining models only had 5 input variables. The second model excluded the friction angle $\left(\mathrm{ANN}_{I I}\right)$, the third excluded the void ratio $\left(\mathrm{ANN}_{I I I}\right)$, and the last one excluded the compacted water content $\left(\mathrm{ANN}_{I V}\right)$. For all models, a single hidden layer was used with two neurons activated by a logistic sigmoid function. The output variable was the apparent cohesion. The back-propagation algorithm was used to train the model with a Bayesian regularization technique to guarantee generalization. The training dataset was made up of 20 samples. The testing dataset consisted of 7 samples. $\mathrm{ANN}_{I V}$ presented the best accuracy.

Neural networks were also used to determine other soil properties. For example, in estimating the shear modulus and damping ratio [201], stress-strain behavior [202, angle of shearing resistance [203], compressive strength [204], soil compaction and permeability [205], preconsolidation pressure [206], deviatoric stress and volumetric strain [207], effective stress [208], and bulk density [209].

\subsubsection{Soil organic matter}

Fidêncio et al. [210] developed an RBF network to determine the organic matter in soils. The 
input variables were the first eight non-normalized scores of the principal component analysis of the soil data samples (which explains $97 \%$ of the data variance). The model outperformed the MLP model, also developed by the authors. The authors concluded that the RBF model is fast, clean and reliable and can be used as a tool to determine organic matter content in soils, as the errors were acceptable for soil laboratories.

\subsubsection{Soil organic carbon}

Were et al. 211] developed and compared an SVM and an MLP models to predict soil organic carbon in the Eastern Mau Forest Reserve, Kenya. The models were used to create prediction maps. The tested input variables were rainfall, land cover, aspect, slope, curvature, TWI, NDVI, PC1, sand, silt, magnesium, calcium, potassium, phosphorus, nitrogen, and $\mathrm{pH}$. The training and testing soil data were randomly split into 176 samples for training and 44 samples for testing. The authors observed that all models overestimated the organic carbon stocks and had equivalent accuracy performance.

\subsubsection{Ground temperature}

Kalogirou et al. 212] developed an ANN model for the generation of $10 \mathrm{~km}$ grid geothermal maps of ground temperature at 20,50, and $100 \mathrm{~m}$ in Cyprus. The 9 input variables were lithology class (22 types), elevation, minimum, mean, and maximum annual ambient temperature, rainfall, $x$ and $y$-coordinates, and depth. Three slabs in a single hidden layer, with 5 neurons each, were used and activated with different functions - Gaussian, Gaussian complement, and hyperbolic tangent functions. The output layer had a single neuron activated by a logistic function. The backpropagation algorithm trained the model. The training and testing datasets were obtained from recorded data from 41 boreholes. After eliminating incomplete measurements, the total data represented 112 patterns; from these, 90 patterns were used for training and 22 for testing. The authors considered the model to be suitable for engineers in design of geothermal systems.

\subsubsection{Thermal resistivity}

Erzin et al. 213] implemented an MLP model for the prediction of the thermal resistivity of clay, silt, silty, fine and coarse-sands. Six input variables were the water content, soil dry unit weight, and particle diameter finer than $10 \%, 30 \%, 50 \%$, and $70 \%$. The hidden layer had 8 neurons. The output variable was the soil thermal resistivity. Both hidden and output layers were activated by a logistic sigmoid transfer function. The Levenberg-Marquardt algorithm was used for training. The training and testing datasets were gathered from different soil measurements with a thermal probe. 


\subsubsection{Thermal conductivity}

Kalogirou et al. [214] implemented an ANN, similar to a previous study [212], for the estimation of ground thermal conductivity in Cyprus. The estimated information was then used to generate geothermal maps for conductivity for the first $100 \mathrm{~m}$ in dry soil. 8 input variables were usedlithology class (22 types), elevation, minimum, mean, and maximum annual ambient temperature, rainfall, and $x$ and $y$-coordinates. In a single hidden layer, with three slabs having 3 neurons each, which was activated by Gaussian, Gaussian complement, and hyperbolic tangent functions. A single output variable activated by a logistic function was used to predict thermal conductivity. The model was trained using the back-propagation algorithm. The datasets used for training and testing of the model were measurements recorded from 41 boreholes. From those, 33 were used for training and 8 for testing. The geothermal map was created by determining the conductivity in a $10 \mathrm{~km}$ interval grip.

\subsubsection{Electric resistivity}

Erzin et al. 215] developed an ANN model for the prediction of the soil electric resistivity. From several tested structures, the one with the best performance had three input variables - thermal resistivity, soil type, and saturation. A single hidden layer had 7 neurons that were activated by the sigmoid function. The single output variable was the thermal resistivity. The Levenberg-Marquardt algorithm was used in training. The training, testing, and validation datasets were in total 236 soil samples, which were divided into 132, 57, and 47 samples, respectively. The authors compared the ANN to two multiple regression analysis models and the former outperformed all. They concluded that this approach was an inexpensive and efficient substitute to laboratory testing.

\subsubsection{Hydraulic properties}

Schaap et al. 216 developed a computer program (ROSETTA) comprising a set of five hierarchical pedotransfer functions, based on 60 to 100 neural networks combined with the bootstrap method, for the estimation of water retention and hydraulic conductivity of soils. The training of the models was carried out using 2134 soil samples of water retention and 1541 samples for hydraulic conductivity. The authors noticed that ROSETTA program performed reasonably well when several predictors are used (texture, bulk density, one or more retention points) and, despite lower accuracy otherwise (textural classes only), the models were still useful in cases of missing measured data.

Minasny and McBratney [217] implemented an FNN model to predict van Genutchen pedotransfer function parameters for soil water retention. The process consisted in fitting the predicted parameters with the measured data, instead of training the network to fit the estimated parameters. Two models were built with different number of input variables - three $\left(\mathrm{FNN}_{3}\right)$ and four inputs 
$\left(\mathrm{FNN}_{4}\right)$. The $\mathrm{FNN}_{3}$ had clay, silt, and sand percentage as input variables. The $\mathrm{FNN}_{4}$ includes a fourth variable, the bulk density. Both models had a single hidden layer with 4 neurons activated by the hyperbolic tangent function. The output variables were four vector parameters - residual and saturated water content, and scaling and curve shape factors. The training was carried out by the Levenberg-Marquardt algorithm. The modeling datasets were collected from previous published works on Australian soil properties and water retention (484 and 378 samples for training and testing, respectively), and GRIZZLY database of soil samples in different countries (660 samples for testing). When compared with other approaches, the authors realized that the proposed models outperformed other neural network models, such as ROSETTA [216], at least by $5 \%$ and $13 \%$ accuracy for $\mathrm{FNN}_{3}$ and $\mathrm{FNN}_{4}$, respectively.

\subsection{Climate change}

Neural networks started to be used to estimate climate change scenarios since the late 1990s [218 220]. Forecasting long-term climate behavior was complex and had a central problem with great uncertainties associated with the projections. Important parameters for the climate models were also poorly constrained. In addition to these issues, the calculation of probability density functions required a large number of simulations, which were limited by computation time. To respond to these issues, Knutti et al. 221] developed an MLP model trained with synthetic data from climate simulations as a surrogate model to a climate change ensemble method. The neural network model consisted of 10 input variables and 10 neurons in the hidden layer. The input variables were randomly selected and their prediction capability was tested. The output variables depended on the number of predicted values. The training procedure used the Levenberg-Marquardt algorithm. The training dataset consisted of 500 simulations. The authors concluded that the MLP was two to three orders of magnitude faster than the simulation model and allowed to dramatically improve the efficiency of the ensemble method. The accuracy of the model fell below the error margin of the simulation model, thus being negligible.

Another aspect to consider in climate change predictions is the resolution of the simulated maps. These maps are usually grids containing hundreds of kilometers and are unable to present local sub-grid features and dynamics. To overcome the issue, Tripathi et al. 222 implemented a least square SVM model for statistical downscaling of precipitation at a monthly scale for 29 subdivision stations in India. The input variables were determined using principal component analysis for each meteorological station. The output variable of the model was precipitation. The model was trained using a multifold cross-validation procedure. The total dataset was divided into $70 \%$ for training and $30 \%$ for testing. The modeling datasets were extracted from the National Center for Environmental Prediction in USA. The data spans over January 1948 to December 
2002. Monthly area weighted rainfall data was extracted from the Indian Institute of Tropical Meteorology for the 29 stations. The simulated monthly climate data for the IPCC scenario IS92a, which ranged from January 1948 to December 2100, was obtained from the Canadian Center for Climate Modeling and Analysis. The data was interpolated into a grid with a $2.5^{\circ}$ interval using a linear inverse square interpolation procedure. Five scenarios of precipitation were projected2000-2019, 2020-2039, 2040-2059, 2060-2079, and 2080-2099. The results showed an increase in precipitation in several coastal and northern regions of India and a drop in the precipitation for Kerala and East Madhya Pradesh. When the authors compared the results with conventional ANNs, they concluded that the SVM provided a promising alternative due to its generalization capabilities and lower complexity.

\section{Discussion}

This paper makes a thorough overview of a set of topics, which are generally treated in different research fields but whose interrelations are relevant to be exploited in the quest for a more sustainable built environment, with strong applicability in the planning of cities, design of buildings, and exploration of renewable energy resources. The reviewed methods for estimating, forecasting, classification, and monitoring of renewable energy and environment-related variables allow to identify possible interdisciplinary research opportunities for the development of comprehensive tools to address those issues.

By combining solar, atmospheric, geologic, and hydrologic variables, in a multi-criteria decision aiding process, the forecasting and estimation capabilities of the models could contribute to better planning sustainable cities and infra-structures, to avoid hazardous locations, to minimize environmental impacts, and to optimally manage water and renewable energy resources. As an example, the forecast of extreme atmospheric and hydrologic events, such as high precipitation and river floods, combined with landslide classification, can help to determine which areas are safer to build on; to make use of the forecasted wind speed and direction as input variables for other models that estimate wave level in coastal areas; or, to identify ideal land surface areas that maximize solar radiation availability and avoid soil erosion and liquefaction.

Another example can be drawn from the field of building design. It is frequent to assess a building's thermal performance using dynamic simulation programs. These require weather data from the building's location to produce accurate analysis. However, not all locations have complete, or sometimes not even partial weather data available, due to the cost of setting up and operating a meteorological station. Weather data includes atmospheric, solar, and hydric values, such as hourly air temperature, precipitation, wind speed and direction, direct and diffuse solar radiation, among others. Neural networks may be a sound alternative approach to produce the missing data or even 
generate a full dataset by interpolation from other weather data stations located in surrounding regions. The idea can even be pushed along further by aiming to predict a building's performance using weather data that was forecasted for a future climate change scenario.

In power generation, the use of different prediction variables may help to find opportunities to conjugate renewable energy production from different sources, such as solar, wind, hydro, geothermal, and biomass for a specific region or urban area. The combined use of different models may be used to estimate sharable renewable energy sources at an urban quarter or building scale. The accurate prediction of weather variables may also allow determining future energy consumption, which is important in energy management in a smart grid scenario.

However, the advantages of neural networks in producing fast and accurate forecasts are dependent on the quality of training and testing datasets. The model type and structure also exert great influence in the prediction capability of the model and it is dependent on the nature of the application problem. The type and number of input variables and the model structure strongly influence the algorithm accuracy; therefore, preprocessing methods are required to determine the adequate variables for each model. Nonetheless, neural networks are powerful tools due to their generalization capabilities and robustness.

\section{Conclusion}

This paper offers a comprehensive, integrated review of the application of neural networks to predict solar, atmospheric, hydrologic, and geologic-related variables, which have influence in the performance, salubrity, and security of cities, buildings, and infrastructures. It collects a diversified number of applications and identifies a wide range of output variables that are important to promote sustainable built environments, thus providing a thorough and insightful view on the use of this kind of machine learning techniques.

The prediction of those variables is helpful in urban planning, resource management and power generation, and to better design buildings and other constructions, as these can be combined to develop multi-criteria decision tools that empowers the decision maker by integrating multiple, conflicting and incommensurate evaluations aspects to assess the merits of potential solutions in a vast range of decision settings. These methodological approaches and decision support tools are potentially helpful for urban planners, architects, and engineers; e.g., to determine the renewable energy potential of a region, develop new technological systems that combine renewable energy resources, optimally manage energy and water resources, avoid hazardous locations for new constructions, reduce the environmental impact of cities and buildings, design more energy efficient buildings and healthier cities, and guarantee the quality and availability of renewable energy and water. 
Additionally, the neural networks contribution, as a surrogate method to simulation models and downscaling techniques, on climate change scenarios was also reviewed. It was found that neural networks can be used to estimate missing weather data, interpolate data from information of other locations, and even to build future weather scenarios to test building's performance robustness to different climate change scenarios.

Several of the variables reviewed are very hard to predict due to the uncertainty of the weather phenomena, especially in longer time spans, such as solar radiation, cloud cover, wind speed and direction, precipitation, wave and tide levels, and extreme weather events, or due to suddenness of geologic phenomena like earthquakes. Although there are other variables that are easier to predict due to their stability (lower variation over time), such as land cover classification and erosion, neural networks may still be useful as surrogate methods to destructive testing or costly methods, particularly the ones related to soil characterization. The accuracy of their predictions is generally sufficient for early planning and design stages.

However, for a proficient usage of these techniques, developers should take into consideration that the performance of neural networks models is greatly dependent on the quality of the training set, the model type and structure, and the mechanisms that enhance the model performance (input selection algorithms, filtering, pattern recognition, optimization of the model parameters, etc.). Therefore, there are still research avenues that should be pursued to increase the accuracy of neural networks to determine environment-related variables. Some of the most promising research avenues are:

- selecting the best input variables or developing appropriate variable selection mechanisms;

- developing models more adapted to the requirements and characteristics of real-world problems;

- determining the effectiveness of artificial intelligence in comparison with traditional methods;

- performing systematic comparisons of different artificial intelligence models;

- developing evolutionary approaches capable of continuous learning and adaptive behavior;

- applying filtering and pattern recognition mechanisms to the data; and,

- hybridizing models with other algorithms, namely optimization approaches, to improve overall robustness, accuracy, and reliability. 


\section{Acknowledgements}

The research presented has been developed under the Energy for Sustainability Initiative of the University of Coimbra (UC).

Funding: This work has been financed by the Portuguese Foundation for Science and Technology (FCT) and by the European Regional Development Fund (FEDER) through COMPETE 2020 Operational Program for Competitiveness and Internationalization (POCI) in the framework of the research projects Ren4EEnIEQ (PTDC/EMS-ENE/3238/2014, POCI-01-0145-FEDER-016760, and LISBOA-01-0145-FEDER-016760), UID/MULTI/00308/2013 and SUSpENsE - Sustainable built Environment under Natural Hazards and Extreme Events (CENTRO-01-0145-FEDER-000006), financed by FEDER, Regional Operational Program of the Center (CENTRO2020). Eugénio Rodrigues acknowledges the support provided by the FCT, under PostDoc grant SFRH/BPD/99668/2014.

\section{References}

[1] Turing, A.M.. Computing machinery and intelligence. Mind 1950;59(236):433-460.

[2] Rosenblatt, F.. Principles of Neurodynamics: Perceptrons and the Theory of Brain Mechanisms. Tech. Rep.; Cornell Aeronautical Laboratory; New York, USA; 1961.

[3] Rosenblatt, F.. The perceptron: A probabilistic model for information storage and organization in the brain. Psychological Review 1958;65(6):386-408. doi $10.1037 /$ h0042519

[4] Haykin, S.. Neural networks: a comprehensive foundation. 2nd ed.; Singapore: Pearson Prentice Hall; 1999.

[5] Rumelhart, D.E., Hinton, G.E., Williams, R.J.. Learning representations by back-propagating errors. Nature 1986;323(6088):533-536. doi $10.1038 / 323533 a 0$.

[6] Marquardt, D.W.. An Algorithm for Least-Squares Estimation of Nonlinear Parameters. Journal of the Society for Industrial and Applied Mathematics 1963;11(2):431-441. doi 10.1137/0111030

[7] Wilks, D.S.. Statistical Methods in the Atmospheric Sciences. 2nd ed.; London, UK: Academic Press; 2006.

[8] Moody, J., Darken, C.J.. Fast Learning in Networks of Locally-Tuned Processing Units. Neural Computation 1989;1(2):281-294. doi:10.1162/neco.1989.1.2.281

[9] Specht, D.. A general regression neural network. IEEE Transactions on Neural Networks 1991;2(6):568-576. doi $10.1109 / 72.97934$.

[10] Jang, J.S.. ANFIS: adaptive-network-based fuzzy inference system. IEEE Transactions on Systems, Man, and Cybernetics 1993;23(3):665-685. doi 10.1109/21.256541.

[11] Cortes, C., Vapnik, V.. Support-vector networks. Machine Learning 1995;20(3):273-297. doi 10.1007/ BF00994018

[12] Specht, D.F.. Probabilistic neural networks. Neural Networks 1990;3(1):109-118. doi:10.1016/0893-6080(90) 90049-Q

[13] Kohonen, T.. Self-organized formation of topologically correct feature maps. Biological Cybernetics 1982;43(1):59-69. doi $10.1007 /$ BF00337288

[14] Hansen, L., Salamon, P.. Neural network ensembles. IEEE Transactions on Pattern Analysis and Machine Intelligence 1990;12(10):993-1001. doi $10.1109 / 34.58871$ 
[15] Huang, G.B., Zhu, Q.Y., Siew, C.K.. Extreme learning machine: Theory and applications. Neurocomputing 2006;70(1-3):489-501. doi 10.1016/j.neucom.2005.12.126

[16] Despotovic, M., Nedic, V., Despotovic, D., Cvetanovic, S.. Review and statistical analysis of different global solar radiation sunshine models. Renewable and Sustainable Energy Reviews 2015;52:1869-1880. doi:] 10.1016/j.rser.2015.08.035.

[17] Şenkal, O., Kuleli, T.. Estimation of solar radiation over Turkey using artificial neural network and satellite data. Applied Energy 2009;86(7-8):1222-1228. doi 10.1016/j.apenergy.2008.06.003

[18] Yadav, A.K., Malik, H., Chandel, S.S.. Selection of most relevant input parameters using WEKA for artificial neural network based solar radiation prediction models. Renewable and Sustainable Energy Reviews 2014;31:509-519. doi $10.1016 /$ j.rser.2013.12.008.

[19] Amrouche, B., Le Pivert, X.. Artificial neural network based daily local forecasting for global solar radiation. Applied Energy 2014;130:333-341. doi:10.1016/j.apenergy.2014.05.055.

[20] Ramedani, Z., Omid, M., Keyhani, A., Shamshirband, S., Khoshnevisan, B.. Potential of radial basis function based support vector regression for global solar radiation prediction. Renewable and Sustainable Energy Reviews 2014;39:1005-1011. doi 10.1016/j.rser.2014.07.108.

[21] Olatomiwa, L., Mekhilef, S., Shamshirband, S., Mohammadi, K., Petković, D., Sudheer, C.. A support vector machine-firefly algorithm-based model for global solar radiation prediction. Solar Energy 2015;115:632644. doi $10.1016 /$ j.solener.2015.03.015.

[22] Mohammadi, K., Shamshirband, S., Tong, C.W., Arif, M., Petković, D., Sudheer, C.. A new hybrid support vector machine-wavelet transform approach for estimation of horizontal global solar radiation. Energy Conversion and Management 2015;92:162-171. doi 10.1016/j.enconman.2014.12.050.

[23] Mohammadi, K., Shamshirband, S., Tong, C.W., Alam, K.A., Petković, D.. Potential of adaptive neuro-fuzzy system for prediction of daily global solar radiation by day of the year. Energy Conversion and Management 2015;93:406-413. doi 10.1016/j.enconman.2015.01.021.

[24] Shamshirband, S., Mohammadi, K., Yee, P.L., Petković, D., Mostafaeipour, A.. A comparative evaluation for identifying the suitability of extreme learning machine to predict horizontal global solar radiation. Renewable and Sustainable Energy Reviews 2015;52:1031-1042. doi 10.1016/j.rser.2015.07.173.

[25] Mohandes, M.A., Rehman, S., Halawani, T.O.. Estimation of global solar radiation using artificial neural networks. Renewable Energy 1998;14(1-4):179-184. doi:10.1016/S0960-1481(98)00065-2.

[26] Al-Alawi, S.M., Al-Hinai, H.A.. An ANN-based approach for predicting global radiation in locations with no direct measurement instrumentation. Renewable Energy 1998;14(1-4):199-204. doi 10.1016/S0960-1481(98) 00068-8.

[27] Kemmoku, Y., Orita, S., Nakagawa, S., Sakakibara, T.. Daily insolation forecasting using a multi-stage neural network. Solar Energy 1999;66(3):193-199. doi:10.1016/S0038-092X(99)00017-1.

[28] Mellit, A.. Artificial Intelligence technique for modelling and forecasting of solar radiation data: a review. International Journal of Artificial Intelligence and Soft Computing 2008;1(1):52. doi:10.1504/IJAISC.2008. 021264

[29] Khatib, T., Mohamed, A., Sopian, K.. A review of solar energy modeling techniques. Renewable and Sustainable Energy Reviews 2012;16(5):2864-2869. doi:10.1016/j.rser.2012.01.064.

[30] Diagne, M., David, M., Lauret, P., Boland, J., Schmutz, N.. Review of solar irradiance forecasting methods and a proposition for small-scale insular grids. Renewable and Sustainable Energy Reviews 2013;27:65-76. doi $10.1016 /$ j.rser.2013.06.042

[31] Yadav, A.K., Chandel, S.S.. Solar radiation prediction using Artificial Neural Network techniques: A review. 
Renewable and Sustainable Energy Reviews 2014;33:772-781. doi $10.1016 /$ j.rser.2013.08.055.

[32] Qazi, A., Fayaz, H., Wadi, A., Raj, R.G., Rahim, N.A., Khan, W.A.. The artificial neural network for solar radiation prediction and designing solar systems: a systematic literature review. Journal of Cleaner Production 2015;104:1-12. doi:10.1016/j.jclepro.2015.04.041

[33] Kashyap, Y., Bansal, A., Sao, A.K.. Solar radiation forecasting with multiple parameters neural networks. Renewable and Sustainable Energy Reviews 2015;49:825-835. doi:10.1016/j.rser.2015.04.077.

[34] Kumar, R., Aggarwal, R.K., Sharma, J.D.. Comparison of regression and artificial neural network models for estimation of global solar radiations. Renewable and Sustainable Energy Reviews 2015;52:1294-1299. doi:] 10.1016/j.rser.2015.08.021.

[35] Widén, J., Carpman, N., Castellucci, V., Lingfors, D., Olauson, J., Remouit, F., et al. Variability assessment and forecasting of renewables: A review for solar, wind, wave and tidal resources. Renewable and Sustainable Energy Reviews 2015;44:356-375. doi 10.1016/j.rser.2014.12.019.

[36] Ren, Y., Suganthan, P.N., Srikanth, N.. Ensemble methods for wind and solar power forecasting - A stateof-the-art review. Renewable and Sustainable Energy Reviews 2015;50:82-91. doi 10.1016/j.rser.2015.04.081.

[37] Wang, L., Kisi, O., Zounemat-Kermani, M., Salazar, G.A., Zhu, Z., Gong, W.. Solar radiation prediction using different techniques: model evaluation and comparison. Renewable and Sustainable Energy Reviews 2016;61:384-397. doi 10.1016/j.rser.2016.04.024.

[38] Zhang, J., Zhao, L., Deng, S., Xu, W., Zhang, Y.. A critical review of the models used to estimate solar radiation. Renewable and Sustainable Energy Reviews 2017;70:314-329. doi 10.1016/j.rser.2016.11.124.

[39] Mellit, A., Pavan, A.M.. A 24-h forecast of solar irradiance using artificial neural network: Application for performance prediction of a grid-connected PV plant at Trieste, Italy. Solar Energy 2010;84(5):807-821. doi $10.1016 /$ j.solener.2010.02.006

[40] Sfetsos, A., Coonick, A.H.. Univariate and multivariate forecasting of hourly solar radiation with artificial intelligence techniques. Solar Energy 2000;68(2):169-178. doi 10.1016/S0038-092X(99)00064-X.

[41] Tymvios, F.S., Jacovides, C.P., Michaelides, S.C., Scouteli, C.. Comparative study of Ångström's and artificial neural networks' methodologies in estimating global solar radiation. Solar Energy 2005;78(6):752762. doi $10.1016 /$ j.solener.2004.09.007

[42] Reddy, K.S., Ranjan, M.. Solar resource estimation using artificial neural networks and comparison with other correlation models. Energy Conversion and Management 2003;44(15):2519-2530. doi 10.1016/S0196-8904(03) 00009-8.

[43] Mellit, A., Benghanem, M., Kalogirou, S.A.. An adaptive wavelet-network model for forecasting daily total solar-radiation. Applied Energy 2006;83(7):705-722. doi $10.1016 / \mathrm{j}$.apenergy.2005.06.003.

[44] Paoli, C., Voyant, C., Muselli, M., Nivet, M.L.. Forecasting of preprocessed daily solar radiation time series using neural networks. Solar Energy 2010;84(12):2146-2160. doi 10.1016/j.solener.2010.08.011.

[45] Rehman, S., Mohandes, M.. Artificial neural network estimation of global solar radiation using air temperature and relative humidity. Energy Policy 2008;36(2):571-576. doi:10.1016/j.enpol.2007.09.033.

[46] Sözen, A., Arcaklığlu, E., Özalp, M.. Estimation of solar potential in Turkey by artificial neural networks using meteorological and geographical data. Energy Conversion and Management 2004;45(18-19):3033-3052. doi $10.1016 /$ j.enconman.2003.12.020

[47] Mehleri, E.D., Zervas, P.L., Sarimveis, H., Palyvos, J.A., Markatos, N.C.. Determination of the optimal tilt angle and orientation for solar photovoltaic arrays. Renewable Energy 2010;35(11):2468-2475. doi 10.1016/j. renene.2010.03.006

[48] Marquez, R., Coimbra, C.F.. Forecasting of global and direct solar irradiance using stochastic learning 
methods, ground experiments and the NWS database. Solar Energy 2011;85(5):746-756. doi 10.1016/j.solener. 2011.01.007

[49] Soares, J., Oliveira, A.P., Božnar, M.Z., Mlakar, P., Escobedo, J.F., Machado, A.J.. Modeling hourly diffuse solar-radiation in the city of São Paulo using a neural-network technique. Applied Energy 2004;79(2):201-214. doi $10.1016 /$ j.apenergy.2003.11.004

[50] López, G., Batlles, F.J., Tovar-Pescador, J.. Selection of input parameters to model direct solar irradiance by using artificial neural networks. Energy 2005;30(9):1675-1684. doi:10.1016/j.energy.2004.04.035

[51] Elminir, H.K., Azzam, Y.A., Younes, F.I.. Prediction of hourly and daily diffuse fraction using neural network, as compared to linear regression models. Energy 2007;32(8):1513-1523. doi 10.1016/j.energy.2006.10.010

[52] Mellit, A., Eleuch, H., Benghanem, M., Elaoun, C., Pavan, A.M.. An adaptive model for predicting of global, direct and diffuse hourly solar irradiance. Energy Conversion and Management 2010;51(4):771-782. doi $10.1016 /$ j.enconman.2009.10.034.

[53] Elminir, H.K., Areed, F.F., Elsayed, T.S.. Estimation of solar radiation components incident on Helwan site using neural networks. Solar Energy 2005;79(3):270-279. doi 10.1016/j.solener.2004.11.006

[54] Jacovides, C., Tymvios, F., Boland, J., Tsitouri, M.. Artificial Neural Network models for estimating daily solar global UV, PAR and broadband radiant fluxes in an eastern Mediterranean site. Atmospheric Research 2015;152:138-145. doi $10.1016 /$ j.atmosres.2013.11.004

[55] Dorvlo, A.S.S., Jervase, J.A., Al-Lawati, A.. Solar radiation estimation using artificial neural networks. Applied Energy 2002;71(4):307-319. doi 10.1016/S0306-2619(02)00016-8

[56] Mellit, A., Kalogirou, S.A., Shaari, S., Salhi, H., Hadj Arab, A.. Methodology for predicting sequences of mean monthly clearness index and daily solar radiation data in remote areas: Application for sizing a stand-alone PV system. Renewable Energy 2008;33(7):1570-1590. doi 10.1016/j.renene.2007.08.006.

[57] Janjai, S., Plaon, P.. Estimation of sky luminance in the tropics using artificial neural networks: Modeling and performance comparison with the CIE model. Applied Energy 2011;88(3):840-847. doi:10.1016/j.apenergy. 2010.09 .004

[58] López, G., Gueymard, C.A.. Clear-sky solar luminous efficacy determination using artificial neural networks. Solar Energy 2007;81(7):929-939. doi 10.1016/j.solener.2006.11.001

[59] Wu, Y.k., Hong, J.s.. A literature review of wind forecasting technology in the world. In: 2007 IEEE Lausanne Power Tech. IEEE; 2007, p. 504-509. doi 10.1109/PCT.2007.4538368

[60] Chang, W.y.. A Literature Review of Wind Forecasting Methods. Journal of Power and Energy Engineering 2014;2(April):161-168. doi 10.4236/jpee.2014.24023

[61] Soman, S.S., Zareipour, H., Malik, O., Mandal, P.. A review of wind power and wind speed forecasting methods with different time horizons. In: North American Power Symposium 2010. IEEE; 2010, p. 1-8. doi 10.1109 /NAPS.2010.5619586

[62] Jung, J., Broadwater, R.P.. Current status and future advances for wind speed and power forecasting. Renewable and Sustainable Energy Reviews 2014;31:762-777. doi:10.1016/j.rser.2013.12.054.

[63] Lee, J., Weger, R., Sengupta, S., Welch, R.. A neural network approach to cloud classification. IEEE Transactions on Geoscience and Remote Sensing 1990;28(5):846-855. doi $10.1109 / 36.58972$.

[64] Bankert, R.L.. Cloud Classification of AVHRR Imagery in Maritime Regions Using a Probabilistic Neural Network. Journal of Applied Meteorology 1994;33(8):909-918. doi $10.1175 / 1520-0450(1994) 033\langle 0909:$ CCOAII $\rangle$ $2.0 . \mathrm{CO} ; 2$

[65] Welch, R.M., Sengupta, S.K., Goroch, A.K., Rabindra, P., Rangaraj, N., Navar, M.S.. Polar Cloud and Surface Classification Using AVHRR Imagery: An Intercomparison of Methods. Journal of Applied Meteorology 
1992;31(5):405-420. doi 10.1175/1520-0450(1992)031<0405:PCASCU $\rangle 2.0 . C O ; 2$

[66] Tian, B., Shaikh, M.A., Azimi-Sadjadi, M.R., Haar, T.H.V., Reinke, D.L.. A study of cloud classification with neural networks using spectral and textural features. IEEE Transactions on Neural Networks 1999;10(1):138-151. doi $10.1109 / 72.737500$

[67] Alexiadis, M.C., Dokopoulos, P.S., Sahsamanoglou, H.S.. Wind speed and power forecasting based on spatial correlation models. IEEE Transactions on Energy Conversion 1999;14(3):836-842. doi 10.1109/60.790962

[68] Mohandes, M.A., Rehman, S., Halawani, T.O.. A neural networks approach for wind speed prediction. Renewable Energy 1998;13(3):345-354. doi 10.1016/S0960-1481(98)00001-9.

[69] Krasnopolsky, V.M., Breaker, L.C., Gemmill, W.H.. A neural network as a nonlinear transfer function model for retrieving surface wind speeds from the special sensor microwave imager. Journal of Geophysical Research 1995;100(C6):11033. doi:10.1029/95JC00857

[70] Marzban, C., Stumpf, G.J.. A Neural Network for Tornado Prediction Based on Doppler Radar-Derived Attributes. Journal of Applied Meteorology 1996;35(5):617-626. doi 10.1175/1520-0450(1996)035<0617: ANNFTP $>2.0 . \mathrm{CO} ; 2$,

[71] McCann, D.W.. A Neural Network Short-Term Forecast of Significant Thunderstorms. Weather and Forecasting 1992;7(3):525-534. doi 10.1175/1520-0434(1992)007〈0525:ANNSTF $\rangle 2.0 . C O ; 2$.

[72] Wang, J., Zhang, W., Wang, J., Han, T., Kong, L.. A novel hybrid approach for wind speed prediction. Information Sciences 2014;273:304-318. doi $10.1016 /$ j.ins.2014.02.159

[73] Shukur, O.B., Lee, M.H.. Daily wind speed forecasting through hybrid KF-ANN model based on ARIMA. Renewable Energy 2015;76:637-647. doi $10.1016 /$ j.renene.2014.11.084

[74] Liu, H., Tian, H.Q., Li, Y.F.. Comparison of new hybrid FEEMD-MLP, FEEMD-ANFIS, Wavelet PacketMLP and Wavelet Packet-ANFIS for wind speed predictions. Energy Conversion and Management 2015;89:111. doi $10.1016 /$ j.enconman.2014.09.060

[75] Liu, H., Tian, H., Liang, X., Li, Y.. New wind speed forecasting approaches using fast ensemble empirical model decomposition, genetic algorithm, Mind Evolutionary Algorithm and Artificial Neural Networks. Renewable Energy 2015;83:1066-1075. doi 10.1016/j.renene.2015.06.004

[76] Wang, S., Zhang, N., Wu, L., Wang, Y.. Wind speed forecasting based on the hybrid ensemble empirical mode decomposition and GA-BP neural network method. Renewable Energy 2016;94:629-636. doi $10.1016 / \mathrm{j}$. renene.2016.03.103.

[77] Doucoure, B., Agbossou, K., Cardenas, A.. Time series prediction using artificial wavelet neural network and multi-resolution analysis: Application to wind speed data. Renewable Energy 2016;92:202-211. doi:] 10.1016/j.renene.2016.02.003

[78] Ren, C., An, N., Wang, J., Li, L., Hu, B., Shang, D.. Optimal parameters selection for BP neural network based on particle swarm optimization: A case study of wind speed forecasting. Knowledge-Based Systems 2014;56:226-239. doi 10.1016/j.knosys.2013.11.015.

[79] Azad, H.B., Mekhilef, S., Ganapathy, V.G.. Long-Term Wind Speed Forecasting and General Pattern Recognition Using Neural Networks. IEEE Transactions on Sustainable Energy 2014;5(2):546-553. doi 10. 1109/TSTE.2014.2300150.

[80] Liu, H., Tian, H.q., Li, Y.f., Zhang, L.. Comparison of four Adaboost algorithm based artificial neural networks in wind speed predictions. Energy Conversion and Management 2015;92:67-81. doi:] 10.1016/j.enconman.2014.12.053

[81] Liu, D., Niu, D., Wang, H., Fan, L.. Short-term wind speed forecasting using wavelet transform and support vector machines optimized by genetic algorithm. Renewable Energy 2014;62:592-597. doi:10.1016/j.renene. 


\subsection{8 .011}

[82] Meng, A., Ge, J., Yin, H., Chen, S.. Wind speed forecasting based on wavelet packet decomposition and artificial neural networks trained by crisscross optimization algorithm. Energy Conversion and Management 2016;114:75-88. doi $10.1016 /$ j.enconman.2016.02.013

[83] Liu, H., Tian, H.Q., Liang, X.F., Li, Y.F.. Wind speed forecasting approach using secondary decomposition algorithm and Elman neural networks. Applied Energy 2015;157:183-194. doi 10.1016/j.apenergy.2015.08.014.

[84] Chen, K., Yu, J.. Short-term wind speed prediction using an unscented Kalman filter based state-space support vector regression approach. Applied Energy 2014;113:690-705. doi 10.1016/j.apenergy.2013.08.025

[85] Gardner, M., Dorling, S.. Artificial neural networks (the multilayer perceptron) - a review of applications in the atmospheric sciences. Atmospheric Environment 1998;32(14-15):2627-2636. doi 10.1016/S1352-2310(97) 00447-0.

[86] Krasnopolsky, V.M., Chevallier, F.. Some neural network applications in environmental sciences. Part II: advancing computational efficiency of environmental numerical models. Neural Networks 2003;16(3-4):335-348. doi $10.1016 /$ S0893-6080(03)00026-1.

[87] Lei, M., Shiyan, L., Chuanwen, J., Hongling, L., Yan, Z.. A review on the forecasting of wind speed and generated power. Renewable and Sustainable Energy Reviews 2009;13(4):915-920. doi $10.1016 /$ j.rser.2008.02. 002

[88] Tascikaraoglu, A., Uzunoglu, M.. A review of combined approaches for prediction of short-term wind speed and power. Renewable and Sustainable Energy Reviews 2014;34:243-254. doi: $10.1016 /$ j.rser.2014.03.033.

[89] Ata, R.. Artificial neural networks applications in wind energy systems: a review. Renewable and Sustainable Energy Reviews 2015;49:534-562. doi $10.1016 /$ j.rser.2015.04.166

[90] Mohandes, M.A., Halawani, T.O., Rehman, S., Hussain, A.A.. Support vector machines for wind speed prediction. Renewable Energy 2004;29(6):939-947. doi 10.1016/j.renene.2003.11.009

[91] Sfetsos, A.. A comparison of various forecasting techniques applied to mean hourly wind speed time series. Renewable Energy 2000;21(1):23-35. doi 10.1016/S0960-1481(99)00125-1.

[92] Barbounis, T.G., Theocharis, J.B., Alexiadis, M.C., Dokopoulos, P.S.. Long-term wind speed and power forecasting using local recurrent neural network models. IEEE Transactions on Energy Conversion 2006;21(1):273284. doi:10.1109/TEC.2005.847954.

[93] More, A., Deo, M.. Forecasting wind with neural networks. Marine Structures 2003;16(1):35-49. doi:] 10.1016/S0951-8339(02)00053-9.

[94] Li, G., Shi, J.. On comparing three artificial neural networks for wind speed forecasting. Applied Energy 2010;87(7):2313-2320. doi 10.1016/j.apenergy.2009.12.013

[95] Mohandes, M., Rehman, S., Rahman, S.M.. Estimation of wind speed profile using adaptive neuro-fuzzy inference system (ANFIS). Applied Energy 2011;88(11):4024-4032. doi 10.1016/j.apenergy.2011.04.015.

[96] Potter, C., Negnevitsky, M.. Very Short-Term Wind Forecasting for Tasmanian Power Generation. IEEE Transactions on Power Systems 2006;21(2):965-972. doi 10.1109/TPWRS.2006.873421.

[97] Tagliaferri, F., Viola, I.M., Flay, R.G.J.. Wind direction forecasting with artificial neural networks and support vector machines. Ocean Engineering 2015;97:65-73. doi 10.1016/j.oceaneng.2014.12.026.

[98] Tasadduq, I., Rehman, S.. Application of neural networks for the prediction of hourly mean surface temperatures in Saudi Arabia. Renewable Energy 2002;25(767):545-554. doi 10.1016/S0960-1481(01)00082-9

[99] Hayati, M., Mohebi, Z.. Application of Artificial Neural Networks for Temperature Forecasting. International Journal of Electrical, Computer, Energetic, Electronic and Communication Engineering 2007;1(4):654-658.

[100] Smith, B.A., Hoogenboom, G., McClendon, R.W.. Artificial neural networks for automated year-round 
temperature prediction. Computers and Electronics in Agriculture 2009;68(1):52-61. doi $10.1016 /$ j.compag. 2009.04 .003

[101] Altan Dombaycı, Ö., Gölcü, M.. Daily means ambient temperature prediction using artificial neural network method: A case study of Turkey. Renewable Energy 2009;34(4):1158-1161. doi 10.1016/j.renene.2008.07.007.

[102] Mittal, G., Zhang, J.. Artificial Neural Network-based Psychrometric Predictor. Biosystems Engineering 2003;85(3):283-289. doi 10.1016/S1537-5110(03)00071-0

[103] Shank, D.B., Hoogenboom, G., McClendon, R.W.. Dewpoint Temperature Prediction Using Artificial Neural Networks. Journal of Applied Meteorology and Climatology 2008;47(6):1757-1769. doi:] 10.1175/2007JAMC1693.1

[104] Kişi, Ö., Kim, S., Shiri, J.. Estimation of dew point temperature using neuro-fuzzy and neural network techniques. Theoretical and Applied Climatology 2013;114(3-4):365-373. doi 10.1007/s00704-013-0845-9

[105] Maqsood, I., Khan, M., Abraham, A.. An ensemble of neural networks for weather forecasting. Neural Computing and Applications 2004;13(2):112-122. doi 10.1007/s00521-004-0413-4.

[106] Białobrzewski, I.. Neural modeling of relative air humidity. Computers and Electronics in Agriculture 2008;60(1):1-7. doi 10.1016/j.compag.2007.02.009

[107] Aires, F., Prigent, C., Rossow, W.B., Rothstein, M.. A new neural network approach including first guess for retrieval of atmospheric water vapor, cloud liquid water path, surface temperature, and emissivities over land from satellite microwave observations. Journal of Geophysical Research: Atmospheres 2001;106(D14):1488714907. doi 10.1029/2001JD900085.

[108] Cazorla, A., Olmo, F.J., Alados-Arboledas, L.. Development of a sky imager for cloud cover assessment. Journal of the Optical Society of America A 2008;25(1):29. doi:10.1364/JOSAA.25.000029

[109] Christodoulou, C., Michaelides, S., Pattichis, C.. Multifeature texture analysis for the classification of clouds in satellite imagery. IEEE Transactions on Geoscience and Remote Sensing 2003;41(11):2662-2668. doi 10.1109 /TGRS.2003.815404

[110] Pasini, A., Pelino, V., Potestà, S.. A neural network model for visibility nowcasting from surface observations: Results and sensitivity to physical input variables. Journal of Geophysical Research: Atmospheres 2001;106(D14):14951-14959. doi 10.1029/2001JD900134.

[111] Fabbian, D., de Dear, R., Lellyett, S.. Application of Artificial Neural Network Forecasts to Predict Fog at Canberra International Airport. Weather and Forecasting 2007;22(2):372-381. doi 10.1175/WAF980.1

[112] Manzato, A.. Sounding-derived indices for neural network based short-term thunderstorm and rainfall forecasts. Atmospheric Research 2007;83(2-4):349-365. doi 10.1016/j.atmosres.2005.10.021

[113] Wang, J., Sheng, Z., Zhou, B., Zhou, S.. Lightning potential forecast over Nanjing with denoised soundingderived indices based on SSA and CS-BP neural network. Atmospheric Research 2014;137:245-256. doi: 10.1016/j.atmosres.2013.10.014.

[114] Valipour, M.. How Much Meteorological Information Is Necessary to Achieve Reliable Accuracy for Rainfall Estimations? Agriculture 2016;6(4):53. doi 10.3390/agriculture6040053.

[115] French, M.N., Krajewski, W.F., Cuykendall, R.R.. Rainfall forecasting in space and time using a neural network. Journal of Hydrology 1992;137(1-4):1-31. doi 10.1016/0022-1694(92)90046-X

[116] Hsu, K.l., Gupta, H.V., Sorooshian, S.. Artificial Neural Network Modeling of the Rainfall-Runoff Process. Water Resources Research 1995;31(10):2517. doi 10.1029/95WR01955

[117] Minns, a.W., Hall, M.J.. Artificial neural networks as rainfall-runoff models. Hydrological Sciences Journal 1996;41(3):399-417. doi: $10.1080 / 02626669609491511$.

[118] Tokar, A.S., Johnson, P.A.. Rainfall-runoff modeling using artificial neural networks. Journal of Hydrologic 
Engineering 1999;4(3):232-239. doi 10.1061/(ASCE)1084-0699(1999)4:3(232).

[119] Shamseldin, A.Y.. Application of a neural network technique to rainfall-runoff modelling. Journal of Hydrology 1997;199(3-4):272-294. doi 10.1016/S0022-1694(96)03330-6

[120] Dawson, C.W., Wilby, R.. An artificial neural network approach to rainfall-runoff modelling. Hydrological Sciences Journal 1998;43(1):47-66. doi 10.1080/02626669809492102

[121] Sajikumar, N., Thandaveswara, B.. A non-linear rainfall-runoff model using an artificial neural network. Journal of Hydrology 1999;216(1-2):32-55. doi:10.1016/S0022-1694(98)00273-X.

[122] Smith, J., Eli, R.N.. Neural-Network Models of Rainfall-Runoff Process. Journal of Water Resources Planning and Management 1995;121(6):499-508. doi 10.1061/(ASCE)0733-9496(1995)121:6(499)

[123] Karunanithi, N., Grenney, W.J., Whitley, D., Bovee, K.. Neural Networks for River Flow Prediction. Journal of Computing in Civil Engineering 1994;8(2):201-220. doi:10.1061/(ASCE)0887-3801(1994)8:2(201).

[124] Zealand, C.M., Burn, D.H., Simonovic, S.P.. Short term streamflow forecasting using artificial neural networks. Journal of Hydrology 1999;214(1-4):32-48. doi 10.1016/S0022-1694(98)00242-X.

[125] Thirumalaiah, K., Deo, M.C.. River Stage Forecasting Using Artificial Neural Networks. Journal of Hydrologic Engineering 1998;3(1):26-32. doi 10.1061/(ASCE)1084-0699(1998)3:1(26)

[126] Campolo, M., Andreussi, P., Soldati, A.. River flood forecasting with a neural network model. Water Resources Research 1999;35(4):1191-1197. doi 10.1029/1998WR900086

[127] Jain, S.K., Das, A., Srivastava, D.K.. Application of ANN for Reservoir Inflow Prediction and Operation. Journal of Water Resources Planning and Management 1999;125(5):263-271. doi 10.1061/(ASCE) 0733-9496(1999)125:5(263)

[128] Keiner, L.E., Yan, X.H.. A neural network model for estimating sea surface chlorophyll and sediments from thematic mapper imagery. Remote Sensing of Environment 1998;66(2):153-165. doi 10.1016/S0034-4257(98) 00054-6.

[129] Valipour, M.. Optimization of neural networks for precipitation analysis in a humid region to detect drought and wet year alarms. Meteorological Applications 2016;23(1):91-100. doi 10.1002/met.1533.

[130] Taormina, R., Chau, K.W.. Data-driven input variable selection for rainfall-runoff modeling using binarycoded particle swarm optimization and Extreme Learning Machines. Journal of Hydrology 2015;529:1617-1632. doi $10.1016 /$ j.jhydrol.2015.08.022.

[131] Taormina, R., Chau, K.w.. Neural network river forecasting with multi-objective fully informed particle swarm optimization. Journal of Hydroinformatics 2015;17(1):99 - 112. doi 10.2166/hydro.2014.116.

[132] Tehrany, M.S., Pradhan, B., Jebur, M.N.. Flood susceptibility mapping using a novel ensemble weights-ofevidence and support vector machine models in GIS. Journal of Hydrology 2014;512:332-343. doi 10.1016/j. jhydrol.2014.03.008.

[133] Belayneh, A., Adamowski, J., Khalil, B., Ozga-Zielinski, B.. Long-term SPI drought forecasting in the Awash River Basin in Ethiopia using wavelet neural network and wavelet support vector regression models. Journal of Hydrology 2014;508:418-429. doi 10.1016/j.jhydrol.2013.10.052.

[134] Nourani, V., Hosseini Baghanam, A., Adamowski, J., Kişi, Ö.. Applications of hybrid wavelet-Artificial Intelligence models in hydrology: A review. Journal of Hydrology 2014;514:358-377. doi:10.1016/j.jhydrol. 2014.03.057

[135] Cuadra, L., Salcedo-Sanz, S., Nieto-Borge, J.C., Alexandre, E., Rodríguez, G.. Computational intelligence in wave energy: Comprehensive review and case study. Renewable and Sustainable Energy Reviews 2016;58:12231246. doi $10.1016 /$ j.rser.2015.12.253

[136] Maier, H.R., Dandy, G.C.. Neural networks for the prediction and forecasting of water resources variables: 
A review of modelling issues and applications. Environmental Modelling and Software 2000;15(1):101-124. doi $10.1016 /$ S1364-8152(99)00007-9.

[137] Thirumalaiah, K., Deo, M.C.. Hydrological Forecasting Using Neural Networks. Journal of Hydrologic Engineering 2000;5(2):180-189. doi 10.1061/(ASCE)1084-0699(2000)5:2(180).

[138] Dawson, C., Wilby, R.. Hydrological modelling using artificial neural networks. Progress in Physical Geography 2001;25(1):80-108. doi 10.1191/030913301674775671

[139] Kalteh, A., Hjorth, P., Berndtsson, R.. Review of the self-organizing map (SOM) approach in water resources: Analysis, modelling and application. Environmental Modelling and Software 2008;23(7):835-845. doi $10.1016 /$ j.envsoft.2007.10.001

[140] Hsiang Chen, Y., Chang, F.J.. Evolutionary artificial neural networks for hydrological systems forecasting. Journal of Hydrology 2009;367(1-2):125-137. doi 10.1016/j.jhydrol.2009.01.009

[141] Céréghino, R., Park, Y.S.. Review of the Self-Organizing Map (SOM) approach in water resources: Commentary. Environmental Modelling and Software 2009;24(8):945-947. doi 10.1016/j.envsoft.2009.01.008

[142] Maier, H.R., Jain, A., Dandy, G.C., Sudheer, K.P.. Methods used for the development of neural networks for the prediction of water resource variables in river systems: Current status and future directions. Environmental Modelling and Software 2010;25(8):891-909. doi:10.1016/j.envsoft.2010.02.003

[143] Raghavendra, S., Deka, P.C.. Support vector machine applications in the field of hydrology: A review. Applied Soft Computing Journal 2014;19:372-386. doi 10.1016/j.asoc.2014.02.002.

[144] Yaseen, Z.M., El-shafie, A., Jaafar, O., Afan, H.A., Sayl, K.N.. Artificial intelligence based models for stream-flow forecasting: 2000-2015. Journal of Hydrology 2015;530:829-844. doi 10.1016/j.jhydrol.2015.10.038.

[145] Afan, H.A., El-shafie, A., Mohtar, W.H.M.W., Yaseen, Z.M.. Past, present and prospect of an Artificial Intelligence (AI) based model for sediment transport prediction. Journal of Hydrology 2016;541:902-913. doi $10.1016 /$ j.jhydrol.2016.07.048

[146] Toth, E., Brath, A., Montanari, A.. Comparison of short-term rainfall prediction models for real-time flood forecasting. Journal of Hydrology 2000;239(1-4):132-147. doi 10.1016/S0022-1694(00)00344-9

[147] Hong, Y., Hsu, K.L., Sorooshian, S., Gao, X.. Precipitation Estimation from Remotely Sensed Imagery Using an Artificial Neural Network Cloud Classification System. Journal of Applied Meteorology 2004;43:1834-1853. doi $10.1175 /$ JAM2173.1

[148] Sudheer, K.P., Gosain, A.K., Ramasastri, K.S.. A data-driven algorithm for constructing artificial neural network rainfall-runoff models. Hydrological Processes 2002;16(6):1325-1330. doi 10.1002/hyp.554.

[149] Tokar, A.S., Markus, M.. Precipitation-Runoff Modeling Using Artificial Neural Networks and Conceptual Models. Journal of Hydrologic Engineering 2000;5(2):156-161. doi 10.1061/(ASCE)1084-0699(2000)5:2(156)

[150] Marzban, C., Witt, A.. A Bayesian Neural Network for Severe-Hail Size Prediction. Weather and Forecasting 2001;16(5):600-610. doi 10.1175/1520-0434(2001)016<0600:ABNNFS $>2.0 . C O ; 2$.

[151] Roebber, P.J., Bruening, S.L., Schultz, D.M., Cortinas, J.V.. Improving Snowfall Forecasting by Diagnosing Snow Density. Weather and Forecasting 2003;18(2):264-287. doi $10.1175 / 1520-0434(2003) 018\langle 0264:$ ISFBDS $\rangle$ $2.0 . \mathrm{CO} ; 2$

[152] Simpson, J., McIntire, T.. A recurrent neural network classifier for improved retrievals of areal extent of snow cover. IEEE Transactions on Geoscience and Remote Sensing 2001;39(10):2135-2147. doi 10.1109/36.957276

[153] Tedesco, M., Pulliainen, J., Takala, M., Hallikainen, M., Pampaloni, P.. Artificial neural network-based techniques for the retrieval of SWE and snow depth from SSM/I data. Remote Sensing of Environment 2004;90(1):76-85. doi $10.1016 /$ j.rse.2003.12.002

[154] Kumar, M., Raghuwanshi, N.S., Singh, R., Wallender, W.W., Pruitt, W.O.. Estimating Evapotranspiration 
using Artificial Neural Network. Journal of Irrigation and Drainage Engineering 2002;128(4):224-233. doi: 10.1061/(ASCE)0733-9437(2002)128:4(224).

[155] Kim, T.W., Valdés, J.B.. Nonlinear Model for Drought Forecasting Based on a Conjunction of Wavelet Transforms and Neural Networks. Journal of Hydrologic Engineering 2003;8(6):319-328. doi 10.1061/(ASCE) 1084-0699(2003)8:6(319)

[156] Nayak, P.C., Sudheer, K.P., Rangan, D.M., Ramasastri, K.S.. A neuro-fuzzy computing technique for modeling hydrological time series. Journal of Hydrology 2004;291(1-2):52-66. doi 10.1016/j.jhydrol.2003.12.010.

[157] Chau, K.W.. Particle swarm optimization training algorithm for ANNs in stage prediction of Shing Mun River. Journal of Hydrology 2006;329(3-4):363-367. doi 10.1016/j.jhydrol.2006.02.025

[158] Deo, M.C., Jha, A., Chaphekar, A.S., Ravikant, K.. Neural networks for wave forecasting. Ocean Engineering 2001;28(7):889-898. doi 10.1016/S0029-8018(00)00027-5

[159] Lee, T.L.. Back-propagation neural network for long-term tidal predictions. Ocean Engineering 2004;31(2):225238. doi $10.1016 /$ S0029-8018(03)00115-X

[160] Daliakopoulos, I.N., Coulibaly, P., Tsanis, I.K.. Groundwater level forecasting using artificial neural networks. Journal of Hydrology 2005;309(1-4):229-240. doi 10.1016/j.jhydrol.2004.12.001

[161] Khan, M.S., Coulibaly, P.. Application of Support Vector Machine in Lake Water Level Prediction. Journal of Hydrologic Engineering 2006;11(3):199-205. doi 10.1061/(ASCE)1084-0699(2006)11:3(199).

[162] Coulibaly, P., Anctil, F., Bobée, B.. Daily reservoir inflow forecasting using artificial neural networks with stopped training approach. Journal of Hydrology 2000;230(3-4):244-257. doi:10.1016/S0022-1694(00)00214-6.

[163] Nagy, H.M., Watanabe, K., Hirano, M.. Prediction of Sediment Load Concentration in Rivers using Artificial Neural Network Model. Journal of Hydraulic Engineering 2002;128(6):588-595. doi 10.1061/(ASCE) 0733-9429(2002)128:6(588)

[164] Huang, W., Foo, S.. Neural network modeling of salinity variation in Apalachicola River. Water Research 2002;36(1):356-362. doi 10.1016/S0043-1354(01)00195-6

[165] Sahoo, G.B., Schladow, S.G., Reuter, J.E.. Forecasting stream water temperature using regression analysis, artificial neural network, and chaotic non-linear dynamic models. Journal of Hydrology 2009;378(3-4):325-342. doi $10.1016 /$ j.jhydrol.2009.09.037

[166] Dowla, F.U., Taylor, S.R., Anderson, R.W.. Seismic discrimination with artificial neural networks: Preliminary results with regional spectral data. Bulletin of the Seismological Society of America 1990;80(5):1346-1373.

[167] Goh, A.T.C.. Seismic Liquefaction Potential Assessed by Neural Networks. Journal of Geotechnical Engineering 1994;120(9):1467-1480. doi 10.1061/(ASCE)0733-9410(1994)120:9(1467).

[168] Levine, E.R., Kimes, D.S., Sigillito, V.G.. Classifying soil structure using neural networks. Ecological Modelling 1996;92(1):101-108. doi:10.1016/0304-3800(95)00199-9

[169] Ellis, G.W., Yao, C., Zhao, R., Penumadu, D.. Stress-Strain Modeling of Sands Using Artificial Neural Networks. Journal of Geotechnical Engineering 1995;121(5):429-435. doi 10.1061/(ASCE)0733-9410(1995)121: $5(429)$.

[170] Penumadu, D., Zhao, R.. Triaxial compression behavior of sand and gravel using artificial neural networks (ANN). Computers and Geotechnics 1999;24(3):207-230. doi:10.1016/S0266-352X(99)00002-6.

[171] Schaap, M.G., Leij, F.J., van Genuchten, M.T.. Neural Network Analysis for Hierarchical Prediction of Soil Hydraulic Properties. Soil Science Society of America Journal 1998;62(4):847. doi:10.2136/sssaj1998. $03615995006200040001 x$

[172] Pachepsky, Y.a., Timlin, D., Varallyay, G.. Artificial Neural Networks to Estimate Soil Water Retention from Easily Measurable Data. Soil Science Society of America Journal 1996;60(3):727. doi:10.2136/sssaj1996. 


\section{$03615995006000030007 x$}

[173] Conforti, M., Pascale, S., Robustelli, G., Sdao, F.. Evaluation of prediction capability of the artificial neural networks for mapping landslide susceptibility in the Turbolo River catchment (northern Calabria, Italy). Catena 2014;113:236-250. doi $10.1016 /$ j.catena.2013.08.006

[174] Dou, J., Yamagishi, H., Pourghasemi, H.R., Yunus, A.P., Song, X., Xu, Y., et al. An integrated artificial neural network model for the landslide susceptibility assessment of Osado Island, Japan. Natural Hazards 2015;78(3):1749-1776. doi 10.1007/s11069-015-1799-2

[175] Tien Bui, D., Tuan, T.A., Klempe, H., Pradhan, B., Revhaug, I.. Spatial prediction models for shallow landslide hazards: a comparative assessment of the efficacy of support vector machines, artificial neural networks, kernel logistic regression, and logistic model tree. Landslides 2016;13(2):361-378. doi:] 10.1007/s10346-015-0557-6

[176] Nourani, V., Pradhan, B., Ghaffari, H., Sharifi, S.S.. Landslide susceptibility mapping at Zonouz Plain, Iran using genetic programming and comparison with frequency ratio, logistic regression, and artificial neural network models. Natural Hazards 2014;71(1):523-547. doi:10.1007/s11069-013-0932-3.

[177] Hong, H., Pradhan, B., Xu, C., Tien Bui, D.. Spatial prediction of landslide hazard at the Yihuang area (China) using two-class kernel logistic regression, alternating decision tree and support vector machines. Catena 2015;133:266-281. doi $10.1016 /$ j.catena.2015.05.019

[178] Majdi, A., Beiki, M.. Evolving neural network using a genetic algorithm for predicting the deformation modulus of rock masses. International Journal of Rock Mechanics and Mining Sciences 2010;47(2):246-253. doi $10.1016 /$ j.ijrmms.2009.09.011

[179] Beiki, M., Bashari, A., Majdi, A.. Genetic programming approach for estimating the deformation modulus of rock mass using sensitivity analysis by neural network. International Journal of Rock Mechanics and Mining Sciences 2010;47(7):1091-1103. doi 10.1016/j.ijrmms.2010.07.007

[180] Gordan, B., Jahed Armaghani, D., Hajihassani, M., Monjezi, M.. Prediction of seismic slope stability through combination of particle swarm optimization and neural network. Engineering with Computers 2016;32(1):8597. doi $10.1007 / \mathrm{s} 00366-015-0400-7$.

[181] Yılmaz, I., Yuksek, A.G.. An Example of Artificial Neural Network (ANN) Application for Indirect Estimation of Rock Parameters. Rock Mechanics and Rock Engineering 2008;41(5):781-795. doi:] 10.1007/s00603-007-0138-7

[182] Shahin, M.A., Jaksa, M.B.. State of the Art of Artificial Neural Networks in Geotechnical Engineering. Electronic Journal of Geotechnical Engineering 2008;8:1-26.

[183] Cabalar, A.F., Cevik, A., Gokceoglu, C.. Some applications of Adaptive Neuro-Fuzzy Inference System (ANFIS) in geotechnical engineering. Computers and Geotechnics 2012;40:14-33. doi:10.1016/j.compgeo.2011. 09.008

[184] Huang, Y., Wänstedt, S.. The introduction of neural network system and its applications in rock engineering. Engineering Geology 1998;49(3-4):253-260. doi:10.1016/S0013-7952(97)00056-2.

[185] Panakkat, A., Adeli, H.. Recent Efforts in Earthquake Prediction (1990-2007). Natural Hazards Review 2008;9(2):70-80. doi:10.1061/(ASCE)1527-6988(2008)9:2(70)

[186] Lee, S., Ryu, J.H., Won, J.S., Park, H.J.. Determination and application of the weights for landslide susceptibility mapping using an artificial neural network. Engineering Geology 2004;71(3-4):289-302. doi:] 10.1016/S0013-7952(03)00142-X.

[187] Yesilnacar, E., Topal, T.. Landslide susceptibility mapping: A comparison of logistic regression and neural networks methods in a medium scale study, Hendek region (Turkey). Engineering Geology 2005;79(3-4):251- 
266. doi $10.1016 /$ j.enggeo.2005.02.002

[188] Adeli, H., Panakkat, A.. A probabilistic neural network for earthquake magnitude prediction. Neural Networks 2009;22(7):1018-1024. doi:10.1016/j.neunet.2009.05.003

[189] Panakkat, A., Adeli, H.. Neural network models for earthquake magnitude prediction using multiple seismicity indicators. International Journal of Neural Systems 2007;17(01):13-33. doi 10.1142/S0129065707000890

[190] Scarpetta, S., Giudicepietro, F., Ezin, E.C., Petrosino, S., Del Pezzo, E., Martini, M., et al. Automatic Classification of Seismic Signals at Mt. Vesuvius Volcano, Italy, Using Neural Networks. Bulletin of the Seismological Society of America 2005;95(1):185-196. doi 10.1785/0120030075

[191] Goh, A.T.. Probabilistic neural network for evaluating seismic liquefaction potential. Canadian Geotechnical Journal 2002;39(1):219-232. doi:10.1139/t01-073.

[192] Pal, M.. Support vector machines-based modelling of seismic liquefaction potential. International Journal for Numerical and Analytical Methods in Geomechanics 2006;30(10):983-996. doi 10.1002/nag.509

[193] Licznar, P., Nearing, M.. Artificial neural networks of soil erosion and runoff prediction at the plot scale. CATENA 2003;51(2):89-114. doi 10.1016/S0341-8162(02)00147-9.

[194] Chang, D.H., Islam, S.. Estimation of Soil Physical Properties Using Remote Sensing and Artificial Neural Network. Remote Sensing of Environment 2000;74(3):534-544. doi:10.1016/S0034-4257(00)00144-9

[195] Zhao, Z., Chow, T.L., Rees, H.W., Yang, Q., Xing, Z., Meng, F.R.. Predict soil texture distributions using an artificial neural network model. Computers and Electronics in Agriculture 2009;65(1):36-48. doi:] 10.1016/j.compag.2008.07.008

[196] Elawadi, E., Salem, A., Ushijima, K.. Detection of cavities and tunnels from gravity data using a neural network. Exploration Geophysics 2001;32(4):204. doi:10.1071/EG01204.

[197] Sonmez, H., Gokceoglu, C., Nefeslioglu, H., Kayabasi, A.. Estimation of rock modulus: For intact rocks with an artificial neural network and for rock masses with a new empirical equation. International Journal of Rock Mechanics and Mining Sciences 2006;43(2):224-235. doi 10.1016/j.ijrmms.2005.06.007

[198] Singh, R., Kainthola, A., Singh, T.. Estimation of elastic constant of rocks using an ANFIS approach. Applied Soft Computing 2012;12(1):40-45. doi $10.1016 /$ j.asoc.2011.09.010

[199] Yilmaz, I., Kaynar, O.. Multiple regression, ANN (RBF, MLP) and ANFIS models for prediction of swell potential of clayey soils. Expert Systems with Applications 2011;38(5):5958-5966. doi 10.1016/j.eswa.2010.11. 027.

[200] Lee, S., Lee, S., Kim, Y.. An approach to estimate unsaturated shear strength using artificial neural network and hyperbolic formulation. Computers and Geotechnics 2003;30(6):489-503. doi 10.1016/S0266-352X(03) 00058-2.

[201] Cabalar, A.F., Cevik, A.. Modelling damping ratio and shear modulus of sand-mica mixtures using genetic programming. Expert Systems with Applications 2009;36(4):7749-7757. doi $10.1016 /$ j.eswa.2008.09.010.

[202] Banimahd, M., Yasrobi, S., P.K.Woodward, . Artificial neural network for stress-strain behavior of sandy soils: Knowledge based verification. Computers and Geotechnics 2005;32(5):377-386. doi 10.1016/j.compgeo. 2005.06 .002

[203] Kayadelen, C., Günaydın, O., Fener, M., Demir, A., Özvan, A.. Modeling of the angle of shearing resistance of soils using soft computing systems. Expert Systems with Applications 2009;36(9):11814-11826. doi $10.1016 /$ j.eswa.2009.04.008

[204] Dehghan, S., Sattari, G.H., Chehreh Chelgani, S., Aliabadi, M.A.. Prediction of uniaxial compressive strength and modulus of elasticity for Travertine samples using regression and artificial neural networks. Mining Science and Technology (China) 2010;20(1):41-46. doi 10.1016/S1674-5264(09)60158-7 
[205] Sinha, S.K., Wang, M.C.. Artificial Neural Network Prediction Models for Soil Compaction and Permeability. Geotechnical and Geological Engineering 2008;26(1):47-64. doi 10.1007/s10706-007-9146-3.

[206] Çelik, S., Tan, Ö.. Determination of preconsolidation pressure with artificial neural network. Civil Engineering and Environmental Systems 2005;22(4):217-231. doi 10.1080/10286600500383923

[207] Habibagahi, G., Bamdad, A.. A neural network framework for mechanical behavior of unsaturated soils. Canadian Geotechnical Journal 2003;40(3):684-693. doi 10.1139/t03-004

[208] Kayadelen, C.. Estimation of effective stress parameter of unsaturated soils by using artificial neural networks. International Journal for Numerical and Analytical Methods in Geomechanics 2008;32(9):1087-1106. doi:] 10.1002/nag.660.

[209] Tranter, G., Minasny, B., Mcbratney, A.B., Murphy, B., Mckenzie, N.J., Grundy, M., et al. Building and testing conceptual and empirical models for predicting soil bulk density. Soil Use and Management 2007;23(4):437-443. URL: http://doi.wiley.com/10.1111/j.1475-2743.2007.00092.x. doi. 10.1111/j.1475-2743.2007.00092.x

[210] Fidêncio, P.H., Poppi, R.J., de Andrade, J.C.. Determination of organic matter in soils using radial basis function networks and near infrared spectroscopy. Analytica Chimica Acta 2002;453(1):125-134. doi: 10.1016/S0003-2670(01)01506-9.

[211] Were, K., Bui, D.T., Dick, Ø.B., Singh, B.R.. A comparative assessment of support vector regression, artificial neural networks, and random forests for predicting and mapping soil organic carbon stocks across an Afromontane landscape. Ecological Indicators 2015;52:394-403. doi 10.1016/j.ecolind.2014.12.028.

[212] Kalogirou, S.A., Florides, G.A., Pouloupatis, P.D., Panayides, I., Joseph-Stylianou, J., Zomeni, Z.. Artificial neural networks for the generation of geothermal maps of ground temperature at various depths by considering land configuration. Energy 2012;48(1):233-240. doi 10.1016/j.energy.2012.06.045.

[213] Erzin, Y., Rao, B.H., Singh, D.. Artificial neural network models for predicting soil thermal resistivity. International Journal of Thermal Sciences 2008;47(10):1347-1358. doi:10.1016/j.ijthermalsci.2007.11.001.

[214] Kalogirou, S.A., Florides, G.A., Pouloupatis, P.D., Christodoulides, P., Joseph-Stylianou, J.. Artificial neural networks for the generation of a conductivity map of the ground. Renewable Energy 2015;77:400-407. doi $10.1016 /$ j.renene.2014.12.033.

[215] Erzin, Y., Rao, B.H., Patel, A., Gumaste, S., Singh, D.. Artificial neural network models for predicting electrical resistivity of soils from their thermal resistivity. International Journal of Thermal Sciences 2010;49(1):118-130. doi 10.1016/j.ijthermalsci.2009.06.008.

[216] Schaap, M.G., Leij, F.J., van Genuchten, M.T.. Rosetta: a computer program for estimating soil hydraulic parameters with hierarchical pedotransfer functions. Journal of Hydrology 2001;251(3-4):163-176. doi:10.1016/ S0022-1694(01)00466-8

[217] Minasny, B., McBratney, A.B.. The Neuro-m Method for Fitting Neural Network Parametric Pedotransfer Functions. Soil Science Society of America Journal 2002;66(2):352. doi:10.2136/sssaj2002.3520.

[218] Poff, N.L., Tokar, S., Johnson, P.. Stream hydrological and ecological responses to climate change assessed with an artificial neural network. Limnology and Oceanography 1996;41(5):857-863. doi 10.4319/lo.1996.41.5. 0857 .

[219] Clair, T.A., Ehrman, J.M.. Variations in discharge and dissolved organic carbon and nitrogen export from terrestrial basins with changes in climate: A neural network approach. Limnology and Oceanography 1996;41(5):921-927. doi 10.4319/lo.1996.41.5.0921.

[220] Trigo, R., Palutikof, J.. Simulation of daily temperatures for climate change scenarios over Portugal: a neural network model approach. Climate Research 1999;13(1):45-59. doi 10.3354/cr013045 
[221] Knutti, R., Stocker, T.F., Joos, F., Plattner, G.K.. Probabilistic climate change projections using neural networks. Climate Dynamics 2003;21(3-4):257-272. doi 10.1007/s00382-003-0345-1.

[222] Tripathi, S., Srinivas, V., Nanjundiah, R.S.. Downscaling of precipitation for climate change scenarios: A support vector machine approach. Journal of Hydrology 2006;330(3-4):621-640. doi 10.1016/j.jhydrol.2006.04. 030

Table 1: Number of documents per group.

\begin{tabular}{|c|c|c|}
\hline & $\mathbf{n}$ & $\%$ \\
\hline Solar-related & 218 & $13.81 \%$ \\
\hline Solar radiation & 173 & $79.36 \%$ \\
\hline Solar radiation on tilted surface & 11 & $5.05 \%$ \\
\hline Direct and diffuse radiation & 18 & $8.26 \%$ \\
\hline Infrared and ultraviolet radiation & 8 & $3.67 \%$ \\
\hline Clearness index & 6 & $2.75 \%$ \\
\hline Sky luminance & 2 & $0.92 \%$ \\
\hline Luminous efficacy & 1 & $0.46 \%$ \\
\hline Atmospheric-related & 223 & $14.12 \%$ \\
\hline Wind speed & 122 & $54.71 \%$ \\
\hline Wind speed profile & 3 & $1.35 \%$ \\
\hline Wind direction & 7 & $3.14 \%$ \\
\hline Dry bulb temperature & 33 & $14.80 \%$ \\
\hline Wet-bulb temperature & 3 & $1.35 \%$ \\
\hline Dew point temperature & 4 & $1.79 \%$ \\
\hline Relative humidity & 3 & $1.35 \%$ \\
\hline Water vapor and cloud liquid water path & 1 & $0.45 \%$ \\
\hline Cloud classification & 30 & $13.45 \%$ \\
\hline Fog prediction & 7 & $3.14 \%$ \\
\hline Thunderstorm prediction & 10 & $4.48 \%$ \\
\hline Hyrdologic-related & 830 & $52.56 \%$ \\
\hline Precipitation & 191 & $23.01 \%$ \\
\hline Rainfall-runoff & 148 & $17.83 \%$ \\
\hline Hail & 3 & $0.36 \%$ \\
\hline Snowfall & 7 & $0.84 \%$ \\
\hline Snow cover & 11 & $1.33 \%$ \\
\hline Snow depth and snow water equivalent & 13 & $1.57 \%$ \\
\hline Evapotranspiration & 79 & $9.52 \%$ \\
\hline Drought severity index & 25 & $3.01 \%$ \\
\hline River flow & 82 & $9.88 \%$ \\
\hline Flood & 59 & $7.11 \%$ \\
\hline Wave height & 7 & $0.84 \%$ \\
\hline Tide level & 27 & $3.25 \%$ \\
\hline Groundwater level & 64 & $7.71 \%$ \\
\hline Lake level & 16 & $1.93 \%$ \\
\hline Reservoir inflow & 36 & $4.34 \%$ \\
\hline Sediments concentration & 54 & $6.51 \%$ \\
\hline Salinity & 4 & $0.48 \%$ \\
\hline Water temperature & 4 & $0.48 \%$ \\
\hline Geologic-related & 272 & $17.23 \%$ \\
\hline Landslide susceptibility & 35 & $12.87 \%$ \\
\hline Earthquake classification & 58 & $21.32 \%$ \\
\hline Liquefaction prediction & 31 & $11.40 \%$ \\
\hline Erosion estimation & 3 & $1.10 \%$ \\
\hline Soil classification & 4 & $1.47 \%$ \\
\hline Subsurface cavities & 9 & $3.31 \%$ \\
\hline Soil mechanics & 74 & $27.21 \%$ \\
\hline Soil organic matter & 4 & $1.47 \%$ \\
\hline Soil organic carbon & 2 & $0.74 \%$ \\
\hline Ground temperature & 5 & $1.84 \%$ \\
\hline Thermal resistivity & 2 & $0.74 \%$ \\
\hline Thermal conductivity & 1 & $0.37 \%$ \\
\hline Electric resistivity & 7 & $2.57 \%$ \\
\hline Hydraulic properties & 37 & $13.60 \%$ \\
\hline Climate change & 36 & $2.28 \%$ \\
\hline
\end{tabular}


Table 2: Neural networks acronyms and abbreviations.

\begin{aligned} & \hline Description \\ & \hline ADALINE adaptive linear element \\ & ANFIS adaptive neuro-fuzzy inference system \\ & ANN artificial neural network \\ & BNN Bayesian neural network \\ & ELM extreme learning machine \\ & FNN feedforward neural network \\ & GRNN general regression neural network \\ & HN Hopfield network \\ & LAF-MLN local activation feedback multi-layer network \\ & LN linear neural network \\ & MLP multi-layer perceptron network \\ & NARNN non-linear autoregressive neural network \\ & NLN neural logic network \\ & PNN probabilistic neural network \\ & RBF radial basis function network \\ & RNN recurrent neural network \\ & SOFM self-organizing feature map \\ & SVM support vector machine \\ & \hline\end{aligned}




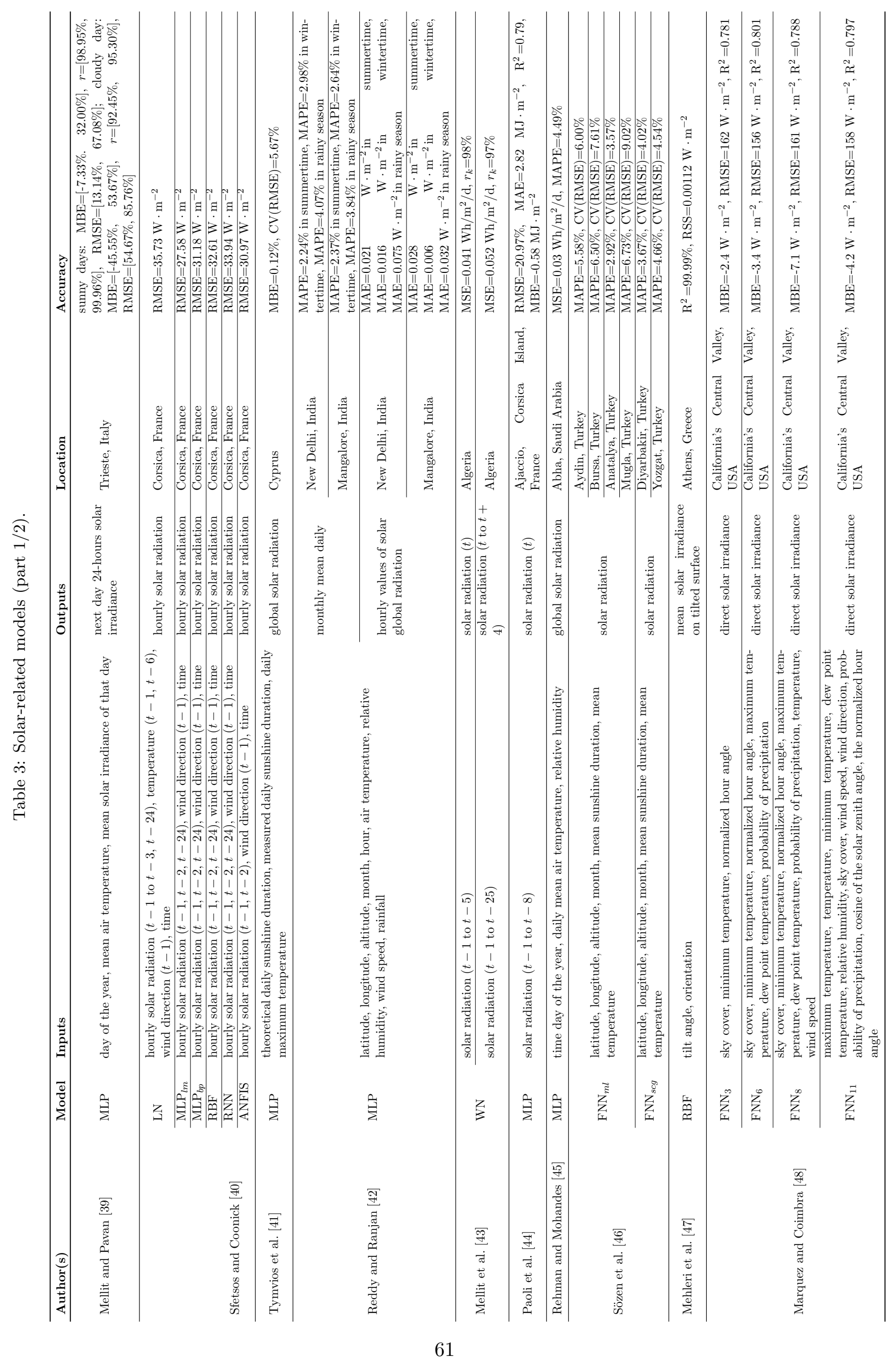




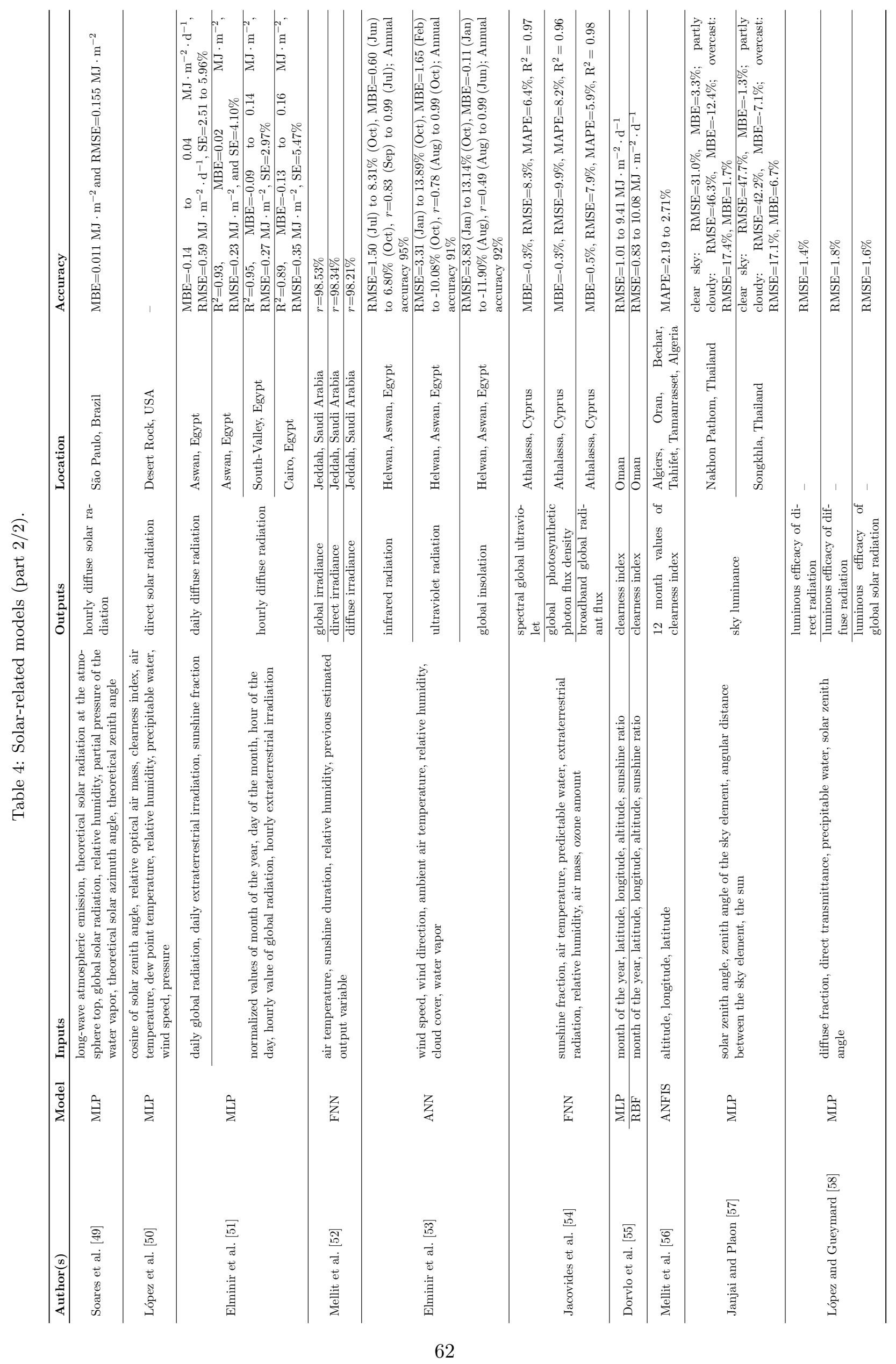




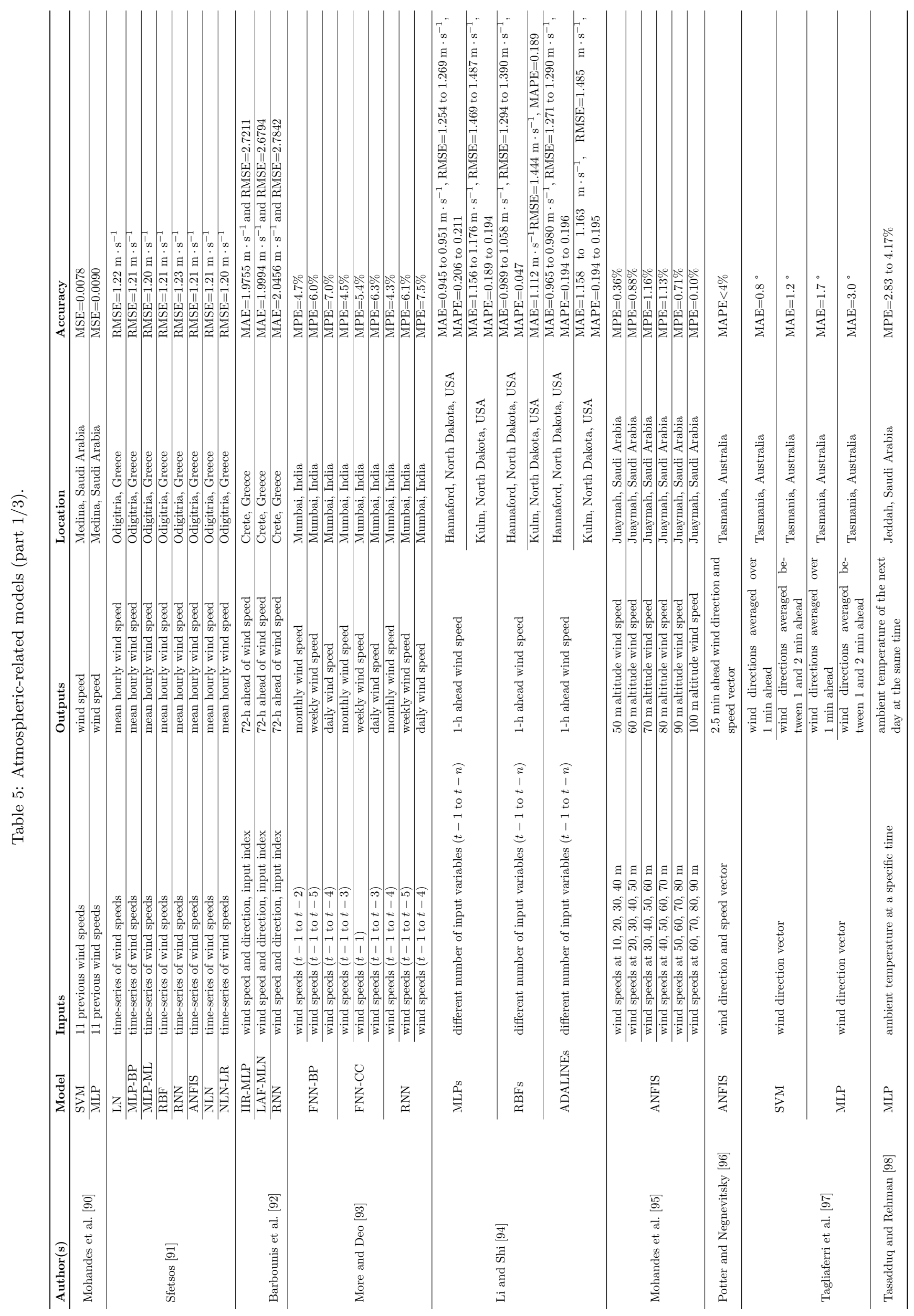




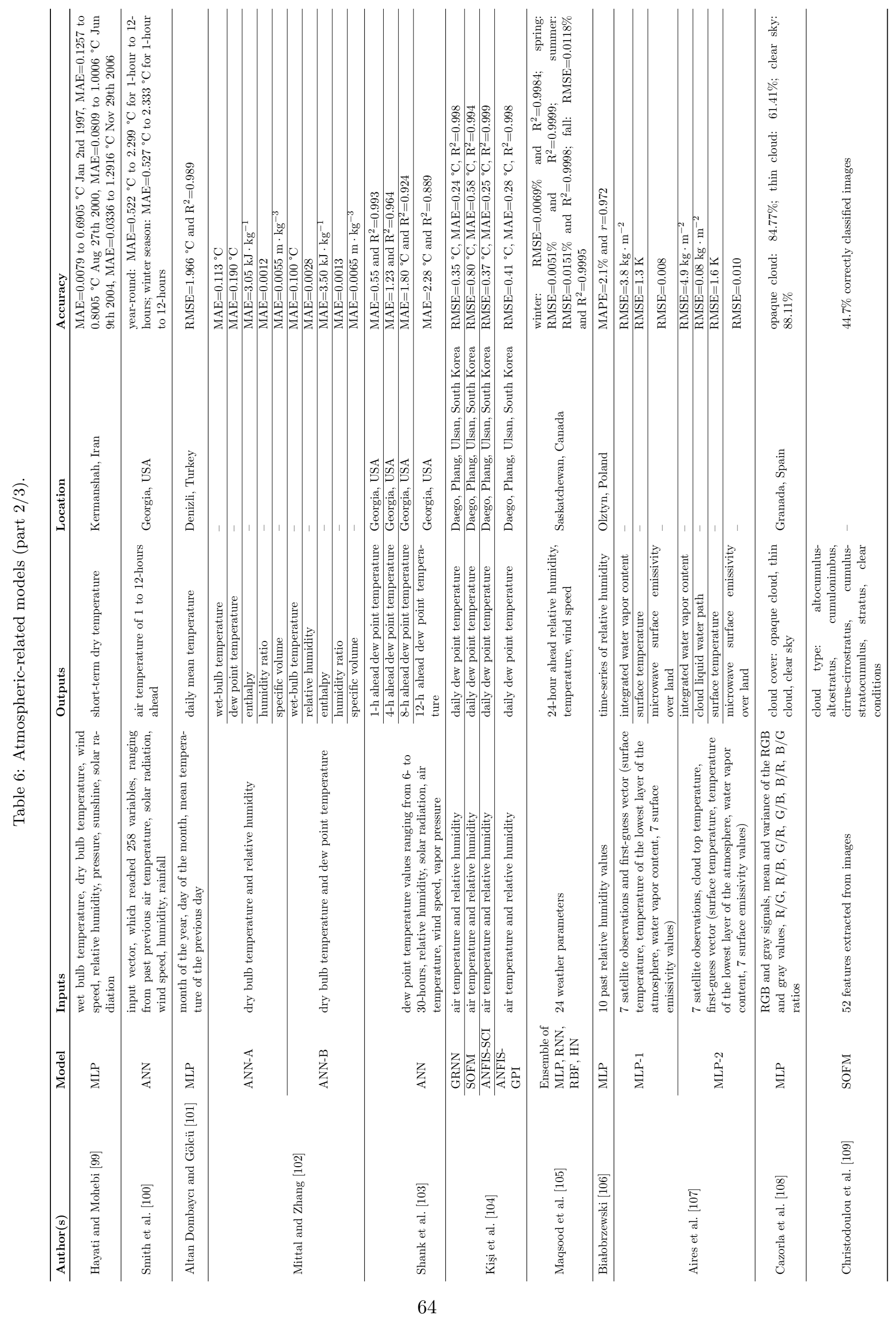




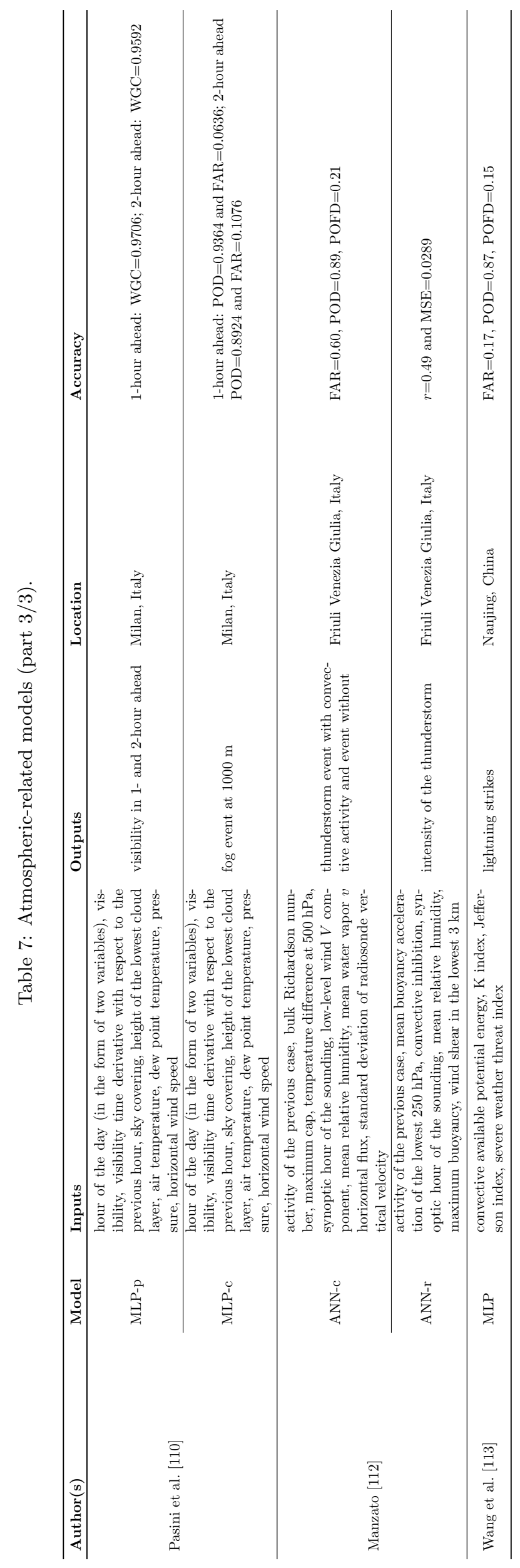




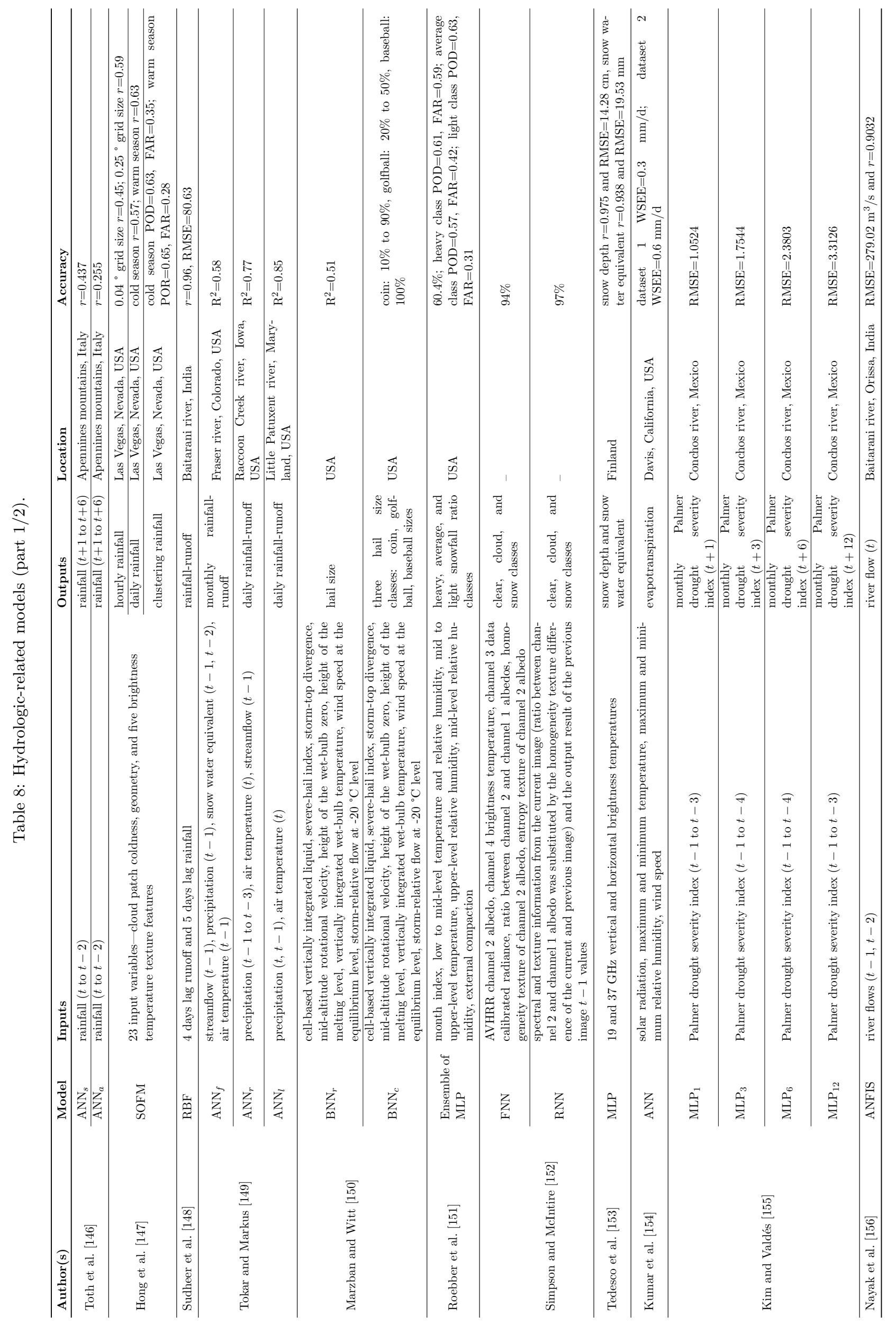




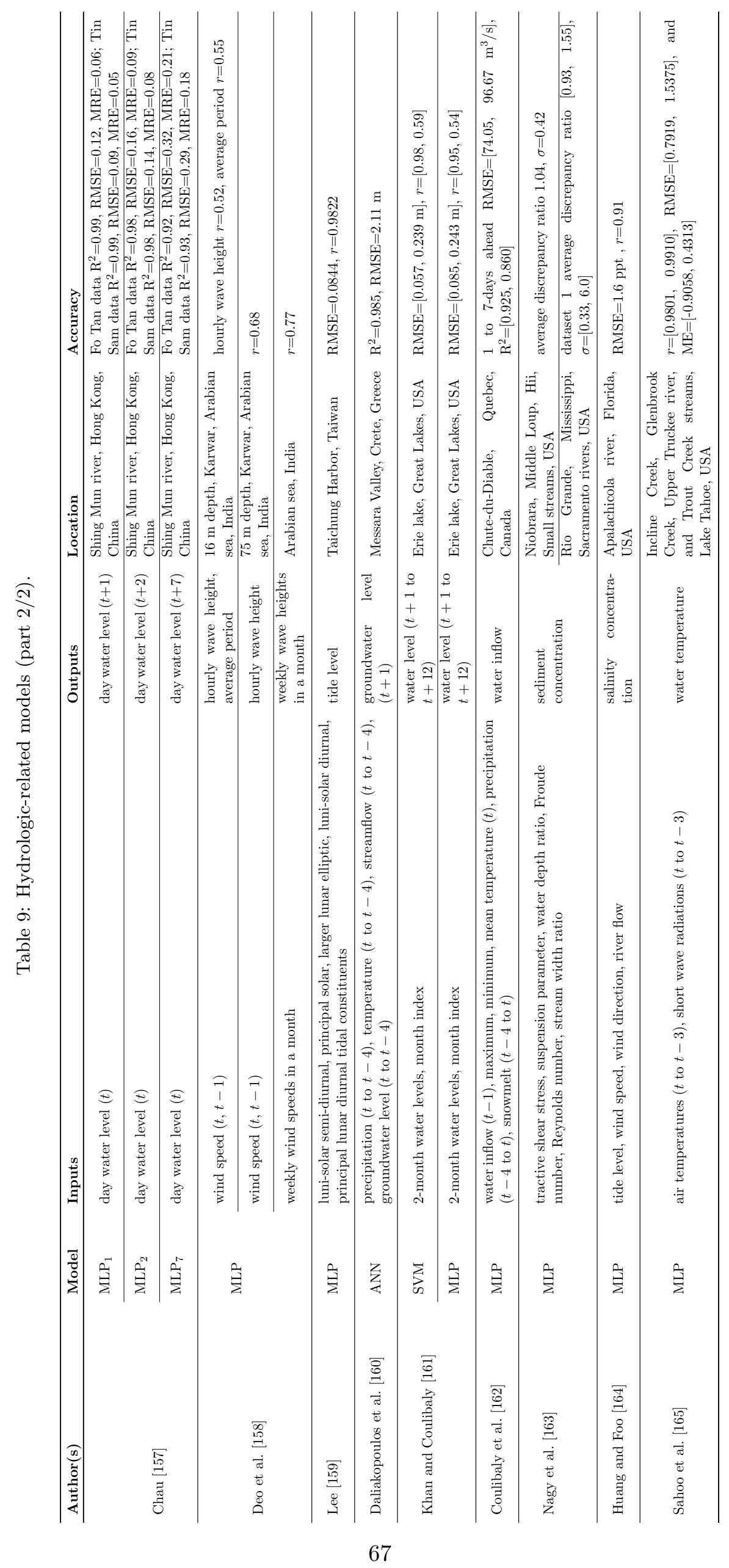




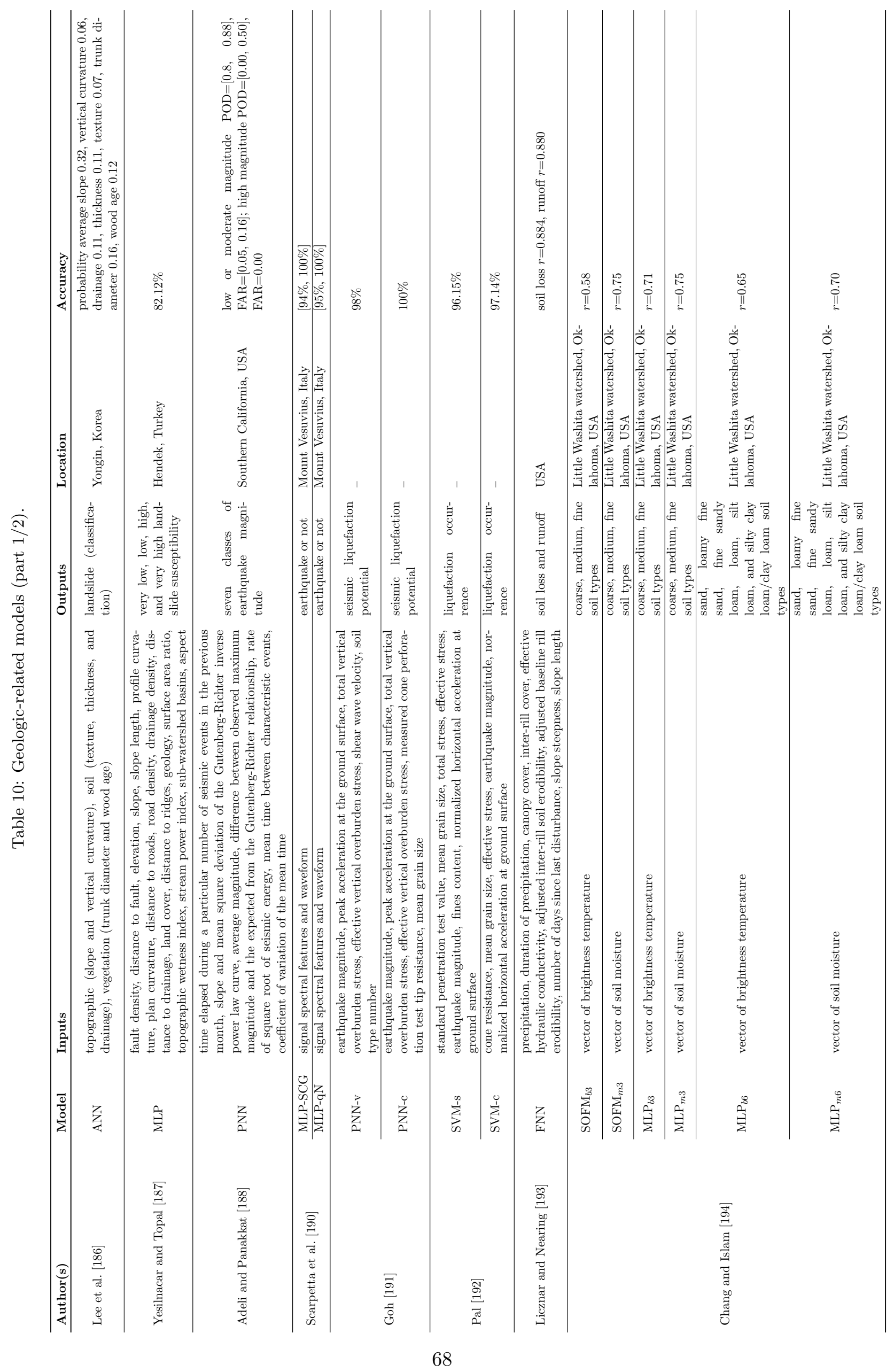




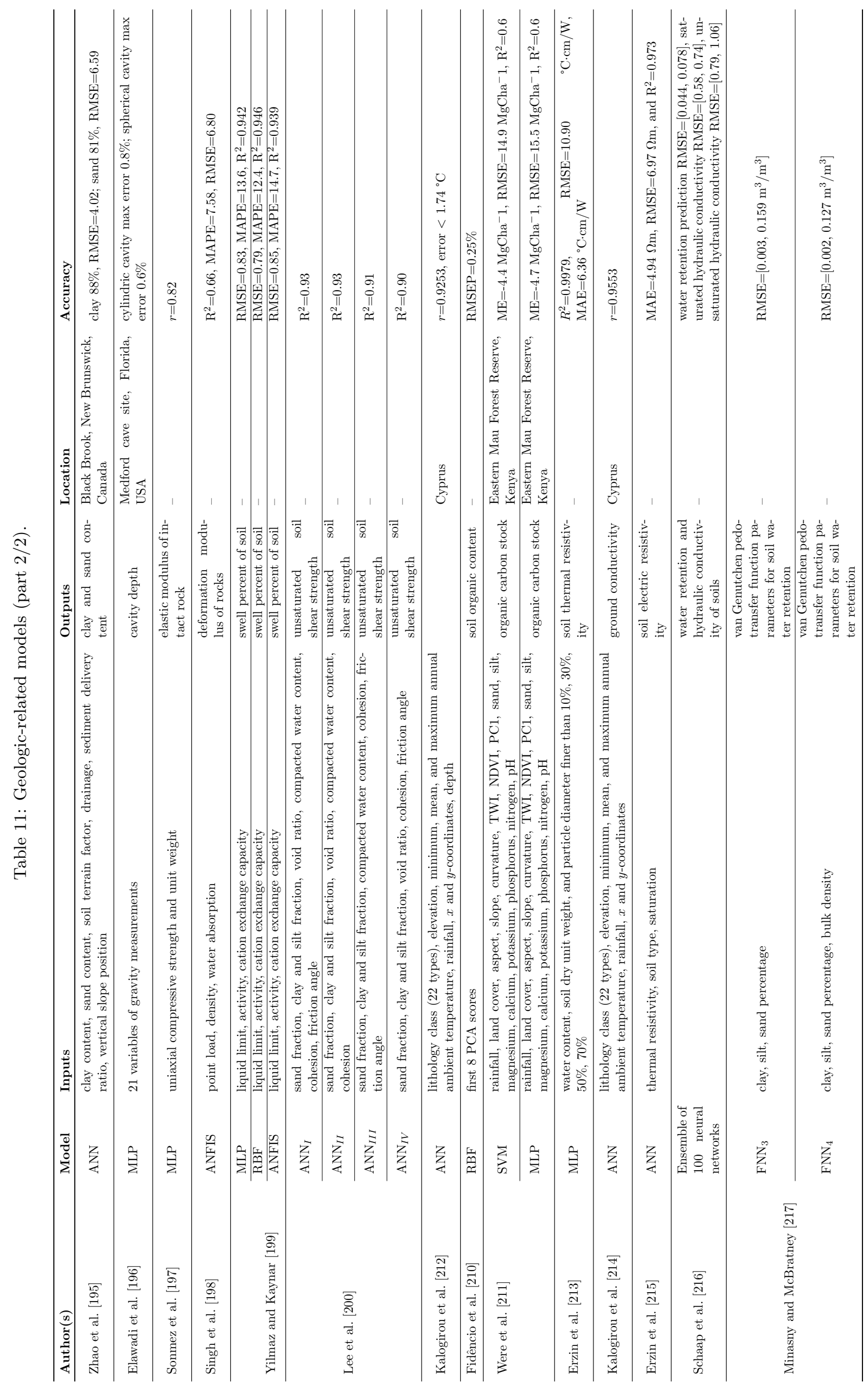

